\title{
Atividades nos espaços abertos públicos: edificações com diferentes recuos frontais, níveis de permeabilidade e usos
}

\author{
Activities in public open space: buildings with different \\ setbacks, levels of permeability and uses
}

\section{Chrystiane Knapp \\ Gabriela Costa da Silva \\ Antônio Tarcísio da Luz Reis}

\section{Resumo}

${ }^{1}$ Chrystiane Knapp

${ }^{1}$ Universidade Federal do Rio Grande do

Porto Alegre - RS - Brasi

${ }^{2}$ Gabriela Costa da Silva 2Universidade Federal do Rio Grande do

Porto Alegre - RS - Brasil

${ }^{3}$ Antônio Tarcísio da Luz Reis ${ }^{3}$ Universidade Federal do Rio Grande do Porto Alegre - RS - Brasil

Recebido em 11/11/20 Aceito em 07/05/21

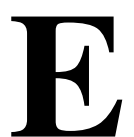

ste artigo investiga os efeitos de edificações com diferentes recuos frontais, níveis de permeabilidade visual e funcional e usos nos térreos, na intensidade de atividades opcionais e necessárias, em movimento e estacionárias nos espaços abertos públicos. O estudo foi realizado em sete quadras no Bairro Cidade Baixa, Porto Alegre, RS, selecionadas com base nas seguintes características: predominância de edificações no alinhamento frontal do lote e de edificações recuadas em relação a ele; e térreos predominantemente residenciais e não residenciais. Os dados foram coletados mediante observações comportamentais, levantamentos físicos e aplicação de questionários respondidos por 194 moradores das sete quadras, e analisados no programa SPSS/PC. Os resultados revelam que quadras com térreos com uso predominantemente não residencial e com maior diversidade de usos, localizados junto à calçada e com portas e janelas para a calçada tendem a atrair maior quantidade de pessoas para o espaço aberto público. Ainda, todas as atividades opcionais, em pé e sentadas, e quase todas as necessárias nesse tipo de quadra, independentemente do período, são maiores do que nas demais quadras analisadas.

Palavras-chave: Atividades no espaço aberto público. Diferentes recuos. Níveis de permeabilidade visual. Níveis de permeabilidade funcional. Usos nos térreos.

\section{Abstract}

This paper investigates the effects of building with different setbacks, levels of visual and functional permeability, and uses on the ground floor, considering the optional and necessary activities, in movement and stationery in the use of public open space. The study was carried out in seven blocks, in the Cidade Baixa neighborhood, Porto Alegre, RS, selected according to the following characteristics: predominance of buildings with street alignment and next to the sidewalks, and buildings with front setback, considering the front limit of the lot; predominance of residential and non-residential uses on the ground floor. The data were collected through behavioral observations, physical measurements and questionnaires applied to residents of the seven selected blocks, resulting in 194 respondents and analyzed in the SPSS/PC program. The results reveal that blocks with ground floors predominantly with nonresidential uses and with a greater diversity of uses, located close to the street with doors and windows facing the sidewalk tend to attract more people and contribute to the use of the public open space. Moreover, all the optional activities, standing and sitting, and almost all the necessary ones, in this type of block, regardless of the period, are larger than in the other analyzed blocks.

Keywords: Activities in public open space. Different building setbacks. Levels of visual permeability. Levels of functional permeability. Uses on the ground floor.

KNAPP, C.; SILVA, G. C. da; REIS, A. T. da L. Atividades nos espaços abertos públicos: edificações com diferentes recuos frontais, níveis de permeabilidade e usos. Ambiente Construído, Porto Alegre, v. 22, n. 1, p. 49-70, jan./mar. 2022. 


\section{Introdução}

As edificações junto ao limite frontal do lote constituem parte dominante do campo visual do transeunte, enquanto edificações recuadas com relação ao passeio público tendem a participar menos de tal campo visual (CULLEN, 1983). No entanto, pequenos recuos frontais, sejam públicos, semiprivados ou privados, quando utilizados como áreas de permanência, com lugares para se sentar, tendem a contribuir para o uso adequado e para a apropriação do espaço aberto público (GEHL, 2010). Por outro lado, recuos frontais substanciais afastam as fachadas do campo visual dos transeuntes e, logo, reduzem as possibilidades de interações com as atividades nos térreos das edificações, o que, conforme já destacado por Gehl (2010) e Jacobs (2011), afeta negativamente o uso do espaço aberto público. Por sua vez, os resultados de um estudo realizado por Netto (2017) indicam que tende a haver redução na circulação de pedestres conforme o aumento do recuo frontal, por exemplo, de 11,5 pedestres/min em quadras com a média de recuos frontais de até $1 \mathrm{~m}$ para 1,9 pedestre/min em quadras com a média de recuos frontais entre $4 \mathrm{~m}$ e $5 \mathrm{~m}$. Contudo, as contagens de pedestres nos segmentos de rua (equivalente a uma quadra) consideradas no referido estudo foram feitas em apenas um dia da semana em cada segmento, sem menção se tais contagens em diferentes segmentos foram realizadas em dias da semana com movimento similar de pedestres ou não.

Ainda, a permeabilidade funcional, caracterizada por portas que possibilitam a passagem de pessoas do espaço aberto público para o interior das edificações e vice-versa (REIS; ELY JUNIOR; EISENHUT, 2019), é drasticamente reduzida em muitas cidades brasileiras devido à delimitação frequente de recuos frontais por muros, os quais tendem a afetar negativamente o movimento de pedestres e a existência de atividades estacionárias no espaço aberto público (NETTO; VARGAS; SABOYA, 2012; FIGUEIREDO, 2018). Especificamente, embora baseados em observações realizadas em apenas um dia da semana (não especificado) em cada um dos 250 segmentos de rua na cidade do Rio de Janeiro, os resultados do estudo realizado por Netto, Vargas e Saboya (2012) revelam a existência de correlações negativas entre a presença de muros e atividades em movimento e estacionárias.

Além disso, pode ter um efeito específico sobre o uso dos espaços abertos públicos a permeabilidade visual, caracterizada por janelas, portas transparentes ou vitrines que permitem a conexão visual entre o espaço aberto público e o interior das edificações (por exemplo, Vivan e Saboya (2019) e Reis, Ely Junior e Eisenhut (2019)). Nesse sentido, a existência de vitrines e produtos expostos para serem observados em vias com maior presença de uso comercial nos térreos tende a contribuir para o uso mais intenso dos espaços abertos públicos (GEHL; KAEFER; REIGSTAD, 2006; MEHTA, 2007; FIGUEIREDO, 2018). A diversidade de objetos que podem ser observados através das áreas transparentes das edificações é apontada como a principal justificativa para os pedestres preferirem caminhar por uma quadra em detrimento de outra, mesmo quando estão apenas de passagem (MEHTA, 2008; FIGUEIREDO, 2018).

Estudo feito em Copenhague pelo Centre for Public Space Research at the School of Architecture (Centro para Pesquisa em Espaço Público na Faculdade de Arquitetura) mostrou que as pessoas tendiam a diminuir a velocidade da caminhada, em torno de $13 \%$, em frente de fachadas mais atraentes e permeáveis, e $25 \%$ das pessoas observadas paravam em frente a esse tipo de fachada. Por outro lado, as pessoas observadas em quadras com fachadas desinteressantes e com pouca permeabilidade tendiam a se apressar, enquanto apenas $1 \%$ das pessoas observadas parava na frente de tais fachadas (GEHL; KAEFER; REIGSTAD, 2006). No estudo realizado por Ewing et al. (2015), o percentual de transparência nas fachadas térreas também aparece como uma das três características expressivas das ruas que contribuem para o movimento de pessoas e para a vitalidade urbana. Nesse sentido, o nível de atividades pode ser até sete vezes maior diante de uma fachada de uso comercial visualmente permeável do que diante de uma fachada de mesmo uso visualmente impermeável (GEHL, 2010).

As atividades dos espaços abertos públicos também são afetadas pelos usos existentes nos térreos das edificações. Conforme pesquisa que compara quadras de três áreas metropolitanas de Boston (Central Square, Coolidge Corner e Davis Square), quando as variáveis físicas são similares (p. ex., calçadas largas e bem mantidas, presença de alguns bancos e outros mobiliários urbanos, prédios com características arquitetônicas históricas, com muitas aberturas para a rua), os usos nos térreos são os geradores de atividades no espaço aberto público (MEHTA, 2007). Nesse sentido, em estudo realizado em 588 quadras de Nova York (EWING et al., 2015) foi identificada correlação positiva entre usos ativos nos térreos das edificações (tais como lojas e restaurantes) e o movimento de pedestres, além de o percentual de tais usos ser um dos três atributos relevantes das ruas que contribuem para a circulação de pessoas. Estudo realizado em Capão da Canoa, RS, também revelou que as quadras com maior movimento de pedestres tendiam a ser caracterizadas por térreos com usos, predominantemente, comercial e de serviços e por maiores percentuais 
de áreas de estar nos recuos frontais, enquanto as quadras com menor movimento tendiam a ser caracterizadas por recuos utilizados como jardins ornamentais e pelo predomínio do uso residencial com portas de garagem e paredes sem aberturas nos térreos (ANTOCHEVIZ; ARSEGO; REIS, 2019). Nesse sentido, pesquisa realizada em Florianópolis (SABOYA; VARGAS; NETTO, 2017) revela a existência de correlação negativa entre o movimento de pedestres e usos residenciais. Por sua vez, os resultados do trabalho de Netto, Vargas e Saboya (2012) revelam a existência de correlações positivas entre o movimento de pedestres, as atividades estacionárias e a diversidade de usos nos térreos (residencial, comércio, serviços e institucional), o que é corroborado pela correlação positiva entre diversidade de usos e movimento de pedestres revelada por outra pesquisa (SABOYA; VARGAS; NETTO, 2017). Essa diversidade de usos tende a aumentar em quadras com maior proporção de edificações no limite do lote, conforme outro estudo realizado em Florianópolis (KRETZER; SABOYA, 2020). Em trabalho realizado na Baía de São Francisco (CERVERO; DUNCAN, 2003) com base no banco de dados da cidade com informações acerca das atividades diárias de pessoas residentes em 15.066 domicílios selecionados aleatoriamente, evidencia-se que ambientes de uso misto com serviços de varejo induzem significativamente à caminhada. Adicionalmente, $o$ uso tende a ser otimizado em quadras com densidade acima de 10 lojas em $100 \mathrm{~m}$ de rua em estudo realizado em Caxias do Sul (FIGUEIREDO, 2018). Nesse sentido, estudos realizados em cidades inglesas revelam a necessidade de, pelo menos, 11 fachadas ativas em $100 \mathrm{~m}$ (MONTGOMERY, 1998), coincidindo com estudo realizado em Boston, onde a existência de 11 ou mais térreos destinados a cafés, restaurantes, bares e lojas como floricultura e livraria, e a serviços que atendam às necessidades diárias ou semanais (p. ex., loja de conveniência, lavanderia) (MEHTA, 2009) contribui para a otimização do uso nas quadras. Por sua vez, estudos realizados em Copenhagen, Changsha (China), Middlesbrough (Reino Unido) e Nova York indicam o mínimo de 15 lojas para que tal uso seja otimizado (GEHL, 2010).

A importância dos efeitos gerados por edificações com diferentes recuos frontais, níveis de permeabilidade e usos nos térreos para a existência de atividades nos espaços abertos também se deve ao fato de que as pessoas tendem a ser atraídas por lugares com presença de outras pessoas e a evitar locais vazios (GEHL; KAEFER; REIGSTAD, 2006; GEHL, 2010; JACOBS, 2011). Contudo, edificações recuadas com atividades nos térreos que pouco ou nada contribuem para os usos dos espaços abertos públicos e com baixo nível de permeabilidade visual e funcional continuam a ser construídas em várias cidades, em diversos países. Dessa forma, é importante a produção de novas evidências acerca dos efeitos que edificações com diferentes recuos frontais, níveis de permeabilidade visual e funcional, e atividades nos térreos causam no uso dos espaços abertos públicos. Soma-se a isso a necessidade de haver melhor identificação e quantificação das atividades necessárias e opcionais, em movimento e estacionárias, a partir de observações de pedestres em vários dias da semana, de maneira a reduzir os efeitos de possíveis alterações pontuais no uso dos espaços abertos públicos. Com base na categorização de atividades concebida por Gehl (2009), as atividades necessárias são aquelas desenvolvidas por obrigação e são menos dependentes das características ambientais, enquanto as atividades opcionais ocorrem voluntariamente, pelo desejo das pessoas, e dependem das condições favoráveis do ambiente.

Assim, o objetivo deste artigo é investigar os efeitos de edificações com diferentes recuos frontais, níveis de permeabilidade visual e funcional, e usos nos térreos, na intensidade de atividades opcionais e necessárias, em movimento e estacionárias, nos espaços abertos públicos.

\section{Método}

A área de estudo está localizada no Bairro Cidade Baixa, Porto Alegre, RS, e foi escolhida em razão da existência de atividades opcionais e necessárias nas ruas e em razão de seu uso misto. Ainda, esse bairro está próximo do Centro Histórico e, principalmente, do Campus Centro da Universidade Federal do Rio Grande do Sul (UFRGS) (Figura 1). O bairro possui 16.522 habitantes, distribuídos em 8.892 domicílios, em uma área de 79 ha, com densidade demográfica de 209,14 hab., a segunda maior da cidade. Adicionalmente, no Bairro Cidade Baixa predominam domicílios particulares permanentes com renda entre 2 e 5 salários mínimos $(2.770-31,15 \%)$, seguido daqueles com renda entre 5 e 10 salários mínimos $(2.598$ - 29,23\%) (INSTITUTO..., 2010).

Assim, para atender ao objetivo deste trabalho, foram selecionadas sete quadras nesse bairro com base nos seguintes parâmetros:

(a) predominância de edificações no alinhamento frontal do lote e de edificações recuadas em relação a ele (máximo de $6 \mathrm{~m}$, conforme o existente); e

(b) térreos das edificações com usos predominantemente residencial e não residencial (Tabela 1, Figura 2).

Atividades nos espaços abertos públicos: edificações com diferentes recuos frontais, níveis de permeabilidade e usos 51 
Figura 1 - Localização do Bairro Cidade Baixa e seu entorno

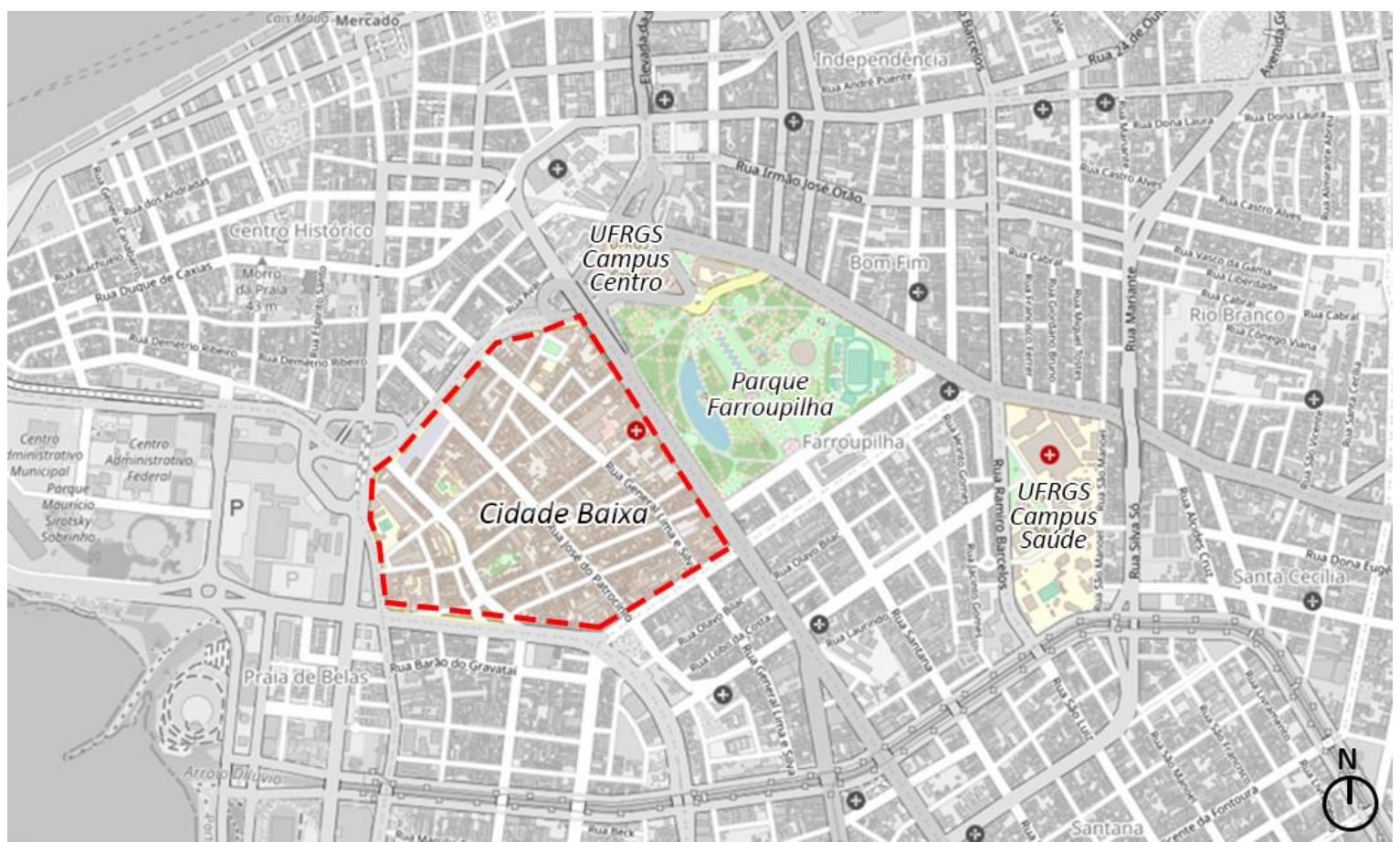

Fonte: adaptado de Open Street Maps (2020).

Ainda, o uso não residencial é caracterizado por pelo menos $25 \%$ de comércios e serviços (Tabela 1). Levantamentos físicos foram realizados nas quadras selecionadas, por meio do Google Street View, visando ao registro das seguintes variáveis:

(a) tipos de usos dos pavimentos térreos (residencial, comercial e de serviço, garagem/estacionamento e sem uso);

(b) comprimento total da quadra, das interfaces no alinhamento e recuadas;

(c) número de edificações (total da quadra, no alinhamento e recuadas);

(d) permeabilidade visual (comprimento de janelas, vitrines e portas de vidro que possibilitem a visualização da rua); e

(e) permeabilidade funcional (número de acessos para pedestres às edificações) (Tabela 1).

A quadra na Rua Leão XIII é formada por três segmentos, enquanto a quadra na Rua Sofia Veloso é formada por dois segmentos (Figura 2).

Em razão dos diferentes comprimentos das quadras, os usos dos pavimentos térreos e os níveis de permeabilidade visual e funcional foram identificados através de taxas, calculadas conforme segue:

(a) taxa de permeabilidade visual: divisão do comprimento total de áreas transparentes nos térreos em ambos os lados da quadra pela soma dos comprimentos dos limites frontais dos lotes nos dois lados da quadra;

(b) taxa de permeabilidade funcional: divisão da quantidade total de acessos para pedestres nos dois lados da quadra pela soma dos comprimentos dos limites frontais dos lotes nos dois lados da quadra; e

(c) taxa de usos dos térreos: divisão da quantidade de cada tipo de uso no térreo pela soma dos comprimentos dos limites frontais dos lotes nos dois lados da quadra. 
Tabela 1 - Características das edificações e interfaces das sete quadras selecionadas

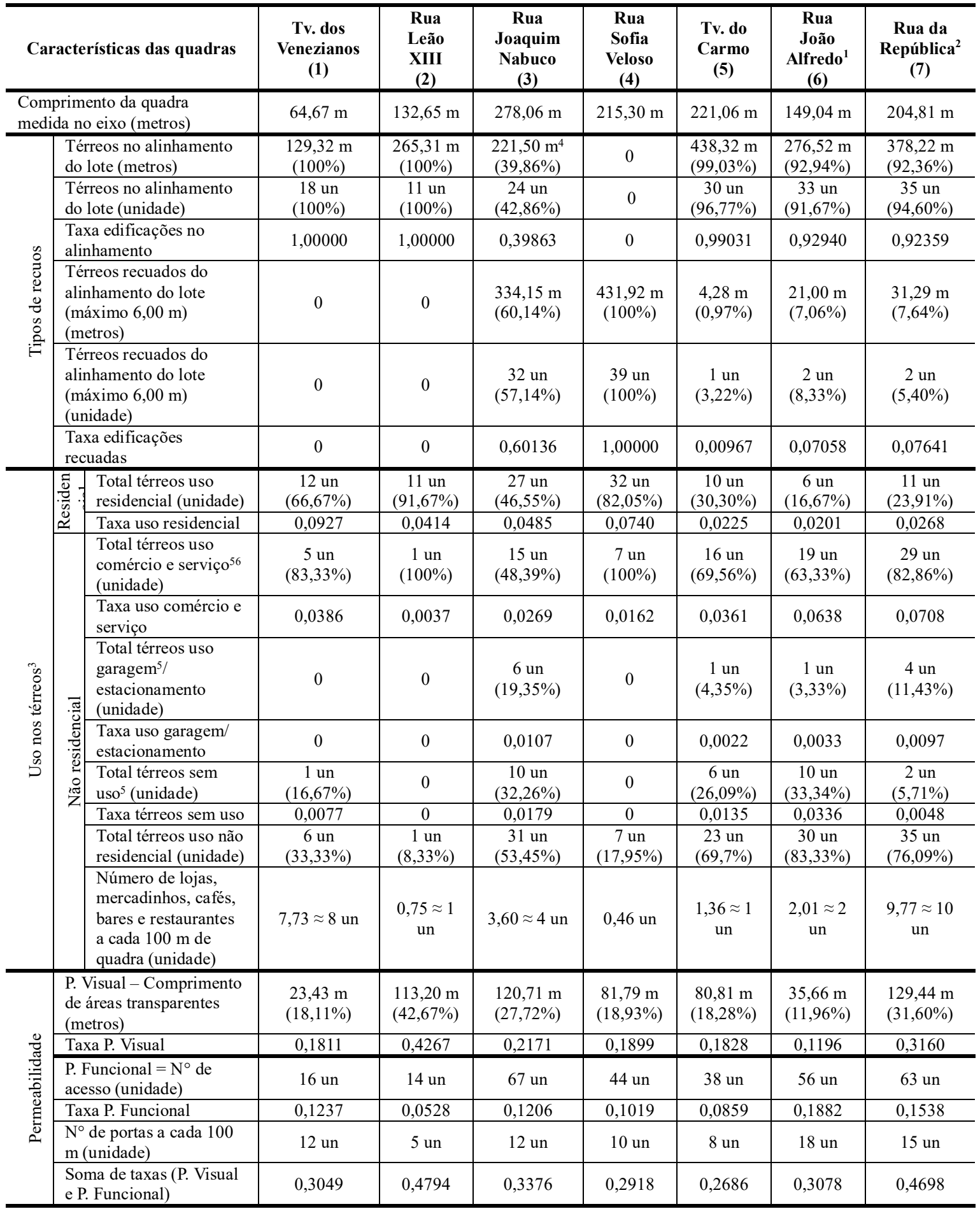

Nota: não foram encontradas quadras no Bairro Cidade Baixa que apresentassem edificações predominantemente recuadas com uso não residencial; 1 - trata-se de quadra com bares abertos a partir das 22h; 2- trata-se de quadra com bares e cafés abertos nos turnos da manhã, tarde e noite; 3 - a quantidade de usos nos térreos se refere ao número de usos diferentes nos térreos, podendo haver em uma mesma edificação mais de um uso; 4- dos 221,50 m de interfaces no alinhamento na Rua Joaquim Nabuco, 52,00 m (23,48\%) correspondem a muros; 5- o total de térreos destinados a serviços e comércios, garagem/estacionamento e sem uso são calculados sobre o valor total dos usos não residenciais; 6 os térreos de uso comércio e serviço são lojas, mercadinhos, cafés, bares, restaurantes, farmácia, cuidados com a saúde bem-estar, creche, lavanderia, imobiliária/assessorias, serviços partidários, espaço religioso, cuidados com pets, serviços de conserto, serviços de segurança, serviços comunitários, serviços de lazer/turismo e serviços de tatuagem. 
Figura 2 - Quadras selecionadas no Bairro Cidade Baixa

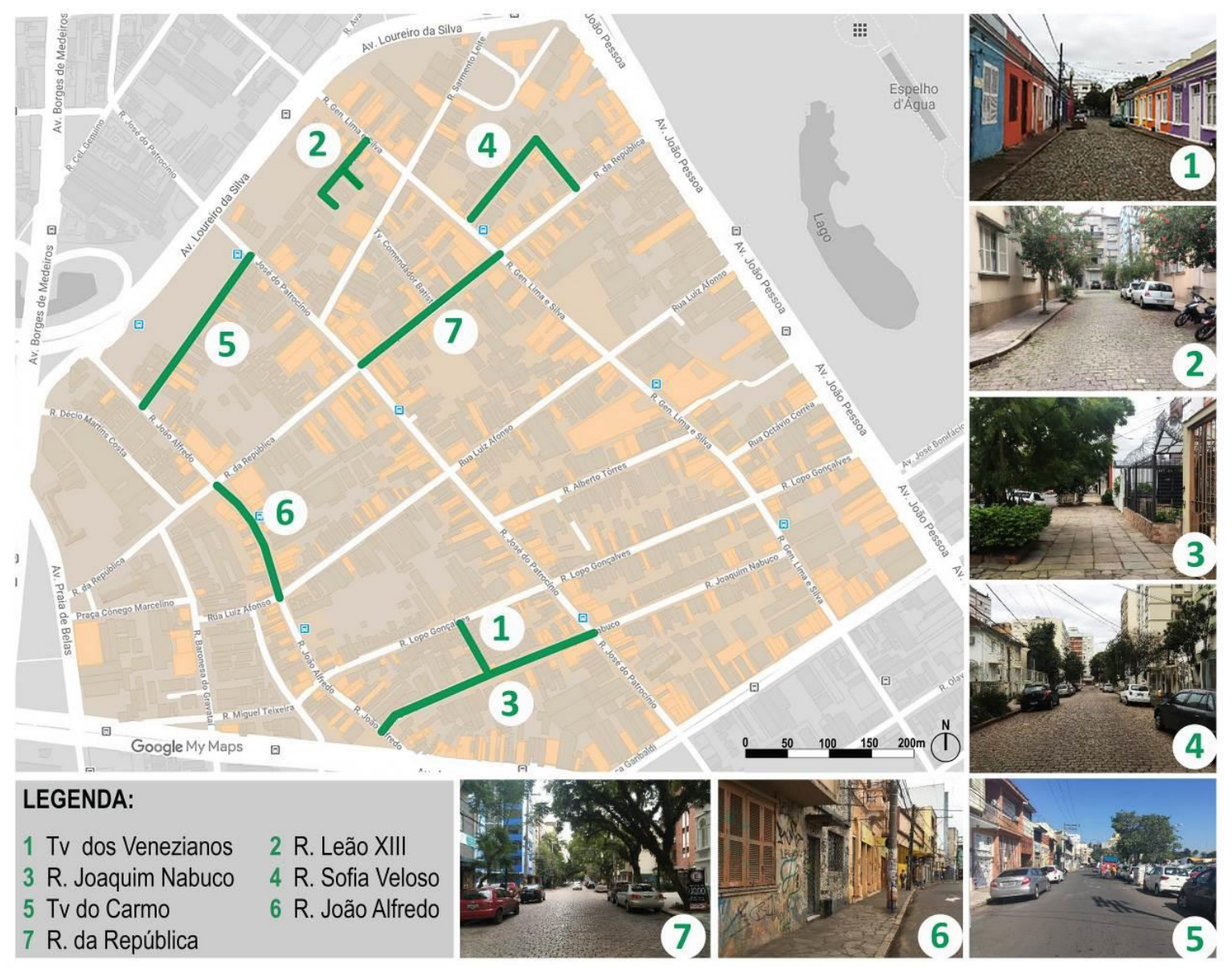

Fonte: adaptado de Google My Maps (2020).

Observações comportamentais foram realizadas com o intuito de relacionar as atividades dos diferentes usuários com as características das quadras selecionadas quanto aos diferentes recuos, níveis de permeabilidade visual e funcional, e usos nos térreos. Essas atividades foram observadas em todas as quadras selecionadas (Figura 2) de 11 a 17 de janeiro de 2018, alternando a ordem de início e fim das observações dentro dos períodos definidos com base nos horários de maior movimento de pessoas na rua, nomeadamente das $12 \mathrm{~h} 30$ às $14 \mathrm{~h}$ (período diurno) e das $18 \mathrm{~h} 30$ às $20 \mathrm{~h}$ (período noturno). O registro das atividades em cada quadra foi realizado simultaneamente por duas pesquisadoras, uma partindo da extremidade de uma das calçadas na quadra e outra partindo da extremidade da calçada oposta, filmando com o celular os pedestres que passavam ou que eram ultrapassadas pelas pesquisadoras durante o percurso. Para percorrer e registrar as atividades em $100 \mathrm{~m}$ de um lado da quadra foi necessário aproximadamente 1 min e $30 \mathrm{~s}$, o que equivale a 3 min para um único pesquisador percorrer $200 \mathrm{~m}$ ou os dois lados de uma quadra com $100 \mathrm{~m}$. Posteriormente, as atividades registradas nos vídeos foram passadas para um mapa comportamental (Figuras 3 e 4).

A quantificação das atividades em opcionais e necessárias, em movimento e estacionárias, em pé e sentadas foi obtida por meio de taxas calculadas com base na divisão da quantidade dessas atividades em cada quadra (durante o dia e durante a noite) pelo comprimento do eixo da quadra. As atividades identificadas como opcionais, fundamentalmente, foram:
(a) passear com cachorro;
(b) fazer atividade física;
(c) conversar com outras pessoas;
(d) olhar vitrines;
(e) sentar-se nas cadeiras de restaurantes/bares/cafeterias localizadas na calçada; 
(f) sentar-se na frente das residências para tomar chimarrão;

(g) crianças brincando; e

(h) crianças passeando acompanhadas de adultos.

Por sua vez, as atividades identificadas como necessárias, essencialmente, foram:

(a) caminhar com sacolas de compras ou com mochila;

(b) caminhar vestindo roupa formal (p. ex., terno);

(c) estar em parada de ônibus;

(d) estar em fila de restaurante;

(e) entregar comida/bebida;

(f) fazer a segurança de algum estabelecimento;

(g) atender clientes sentados nas mesas na calçada (garçons); e

(h) crianças indo para a escola (de mochila e acompanhadas de adulto).

\section{Figura 3 - Mapas comportamentais da quadra na Rua da República}

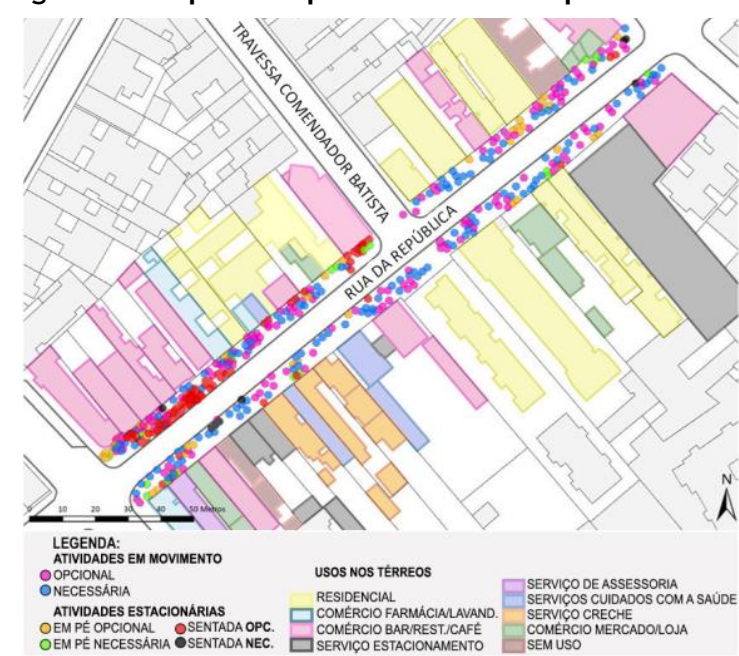

(a) Rua da República - turno diurno

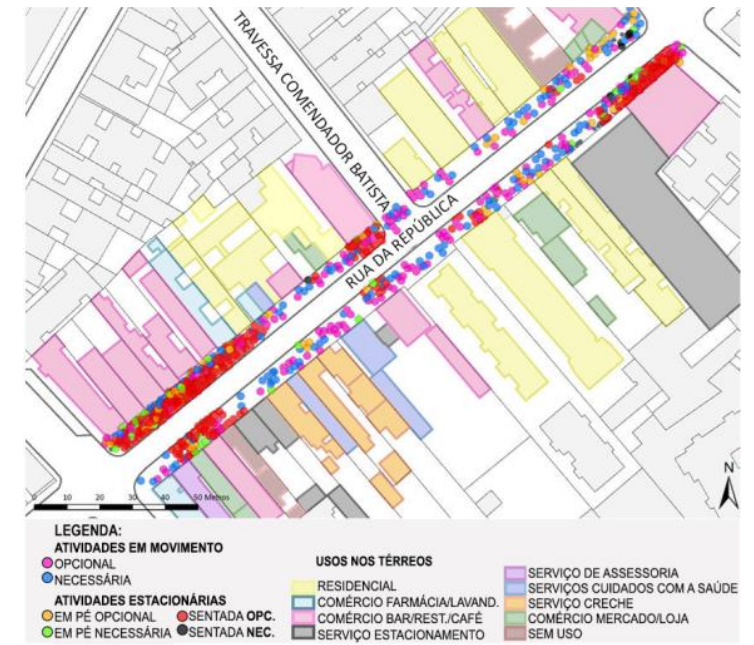

(b) Rua da República - turno noturno

Figura 4 - Mapas comportamentais da quadra na Rua Sofia Veloso

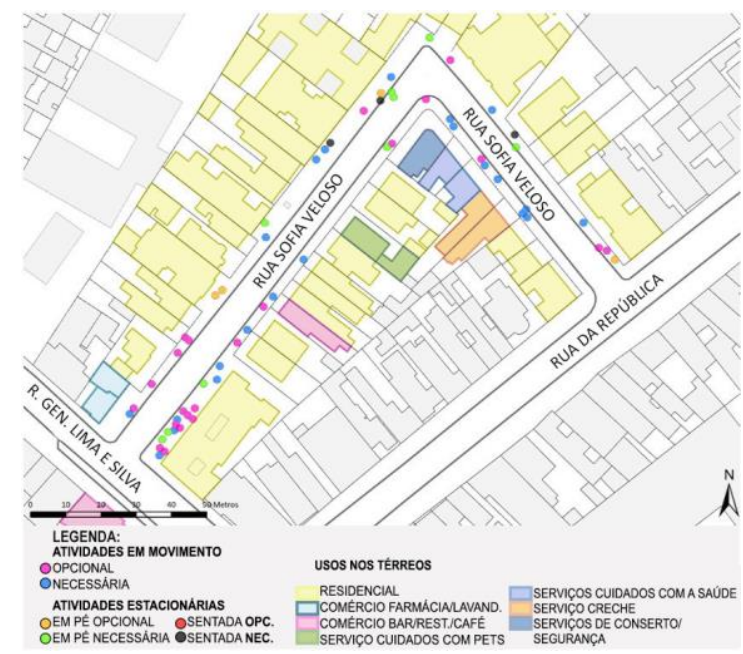

(a) Rua Sofia Veloso - turno diurno

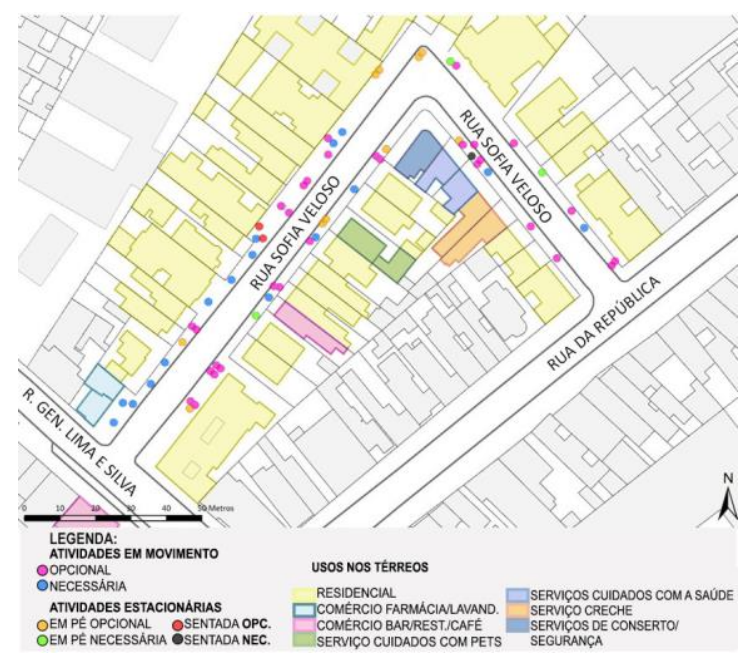

(b) Rua Sofia Veloso - turno noturno 
Adicionalmente, foram aplicados questionários entre os dias 20 de abril e 12 de maio de 2018 para moradores das quadras selecionadas (Figura 2), totalizando 194 respondentes (Tabela 2), que foram contatados:

(a) pessoalmente, nos trechos das quadras escolhidas, onde responderam ao questionário impresso, fornecido pelos pesquisadores, ou informaram seus endereços eletrônicos, para os quais foi encaminhada uma carta apresentando a pesquisa, com orientações sobre como completar o questionário on-line através do programa LimeSurvey; e

(b) através de uma carta de apresentação impressa depositada nas caixas de correspondência das edificações residenciais nos trechos de quadras escolhidas para as análises.

As respostas dos questionários impressos foram transferidas para o LimeSurvey pelos pesquisadores.

Os dados dos questionários no LimeSurvey foram transferidos diretamente para o programa estatístico SPSS/PC e analisados através de frequências e tabulação cruzada (teste estatístico não paramétrico, valor de Phi), tal como na verificação da existência de relação estatisticamente significativa entre o "desejo de transitar ou não na quadra onde mora caso não morasse nela" e as sete quadras, e o "desejo de transitar ou não na quadra onde mora caso não morasse nela" e as justificativas apresentadas. As taxas obtidas através das observações de comportamento foram correlacionadas (teste de correlação paramétrico de Pearson) com as taxas de características das quadras obtidas através do levantamento físico, tal como a verificação da existência de correlação entre taxa de atividades opcionais e taxa de permeabilidade visual, e entre taxa de atividades necessárias e taxa de permeabilidade funcional. Ainda, foram consideradas para esta pesquisa as justificativas citadas por pelo menos $30 \%$ dos respondentes dos questionários em cada trecho de quadra.

\section{Resultados}

\section{Atividades diurnas: edificações com diferentes recuos frontais, níveis de permeabilidade e usos}

\section{Atividades opcionais em movimento}

Conforme as atividades observadas, a maior taxa de atividades opcionais em movimento diurnas está na quadra na Rua da República (0,6982; Figuras 3a e 5), seguida pela quadra na Rua João Alfredo $(0,4831)$, enquanto a menor está na quadra na Rua Leão XIII $(0,0226)$, seguida pelas taxas na quadra da Rua Joaquim Nabuco $(0,0683)$ e na Travessa dos Venezianos $(0,0773)$. As taxas de atividades opcionais em movimento diurnas estão correlacionadas à taxa de permeabilidade funcional (teste de Pearson; Tabela 3) e, logo, tendem a aumentar na medida em que essa taxa aumenta.

Assim, a quadra da Rua da República possui a segunda maior taxa de permeabilidade funcional $(0,1538,15$ acessos em $100 \mathrm{~m}$ de um lado ou 7,5 acessos em cada lado da quadra com $50 \mathrm{~m}$ ) e a maior quantidade de movimento de pessoas em atividades opcionais na quadra durante o dia (Figura 5). Embora não existam correlações entre as taxas de atividades opcionais em movimento diurnas e as taxas de permeabilidade visual, está nessa quadra a segunda maior taxa de permeabilidade visual $(0,3160-31,6 \mathrm{~m}$ de transparência em $100 \mathrm{~m}$ de um lado ou 15,8 m em cada lado da quadra com $50 \mathrm{~m}$ ). Na quadra da Rua João Alfredo está a maior taxa de permeabilidade funcional $(0,1882$ - 18 acessos em $100 \mathrm{~m}$ de um lado da quadra), consequência da presença da segunda maior taxa de edificações $(0,1208-12 \mathrm{em} 100 \mathrm{~m}$ de um lado da quadra). Ainda, esta quadra apresenta a terceira maior taxa de permeabilidades visual e funcional somadas $(0,3078)$, embora possua a menor taxa de permeabilidade visual $(0,1196)$ (Figura 5).

Tabela 2 - Caracterização da amostra de respondentes - moradores das sete quadras

\begin{tabular}{|c|c|c|c|c|c|c|c|}
\hline & $\begin{array}{c}\text { Tv. dos } \\
\text { Venezianos } \\
\mathbf{4}(\mathbf{1 0 0 \% )}\end{array}$ & $\begin{array}{c}\text { Rua Leão } \\
\text { XIII } \\
33 \\
(100 \%)\end{array}$ & $\begin{array}{c}\text { Rua } \\
\text { Joaquim } \\
\text { Nabuco } \\
\mathbf{3 0}(\mathbf{1 0 0 \%}) \\
\end{array}$ & $\begin{array}{c}\text { Rua Sofia } \\
\text { Veloso } \\
32 \\
(100 \%)\end{array}$ & $\begin{array}{c}\text { Tv.do } \\
\text { Carmo } \\
\mathbf{3 2} \\
(\mathbf{1 0 0 \%}) \\
\end{array}$ & $\begin{array}{c}\text { Rua João } \\
\text { Alfredo } \\
\mathbf{3 0} \\
(100 \%)\end{array}$ & $\begin{array}{c}\text { Rua da } \\
\text { República } \\
33 \\
(100 \%)\end{array}$ \\
\hline \multicolumn{8}{|c|}{ Gênero } \\
\hline Feminino & $1(25)$ & $14(42,4)$ & $16(53,3)$ & $14(43,8)$ & $18(56,3)$ & $21(70)$ & $19(57,6)$ \\
\hline Masculino & $3(75)$ & $19(57,6)$ & $14(46,7)$ & $18(56,3)$ & $14(43,8)$ & $9(30)$ & $14(42,4)$ \\
\hline \multicolumn{8}{|c|}{ Faixa Etária } \\
\hline Entre 18 e 30 anos & $1(25)$ & $11(33,3)$ & $5(16,7)$ & $10(31,3)$ & $5(15,6)$ & $9(30)$ & $4(12,1)$ \\
\hline Entre 31 e 65 anos & $3(75)$ & $18(54,5)$ & $14(46,7)$ & $14(43,8)$ & $21(65,6)$ & $19(63,3)$ & $23(69,7)$ \\
\hline Mais de 65 anos & 0 & $4(12,1)$ & $11(36,7)$ & $8(25)$ & $6(18,8)$ & $2(6,7)$ & $6(18,2)$ \\
\hline
\end{tabular}

56 Knapp, C.; Silva, G. C. da; Reis, A. T. da L. 
Figura 5 - Taxas de atividades opcionais e necessárias diurnas nas quadras, níveis de permeabilidade e usos nos térreos

a) Atividades opcionais diurnas

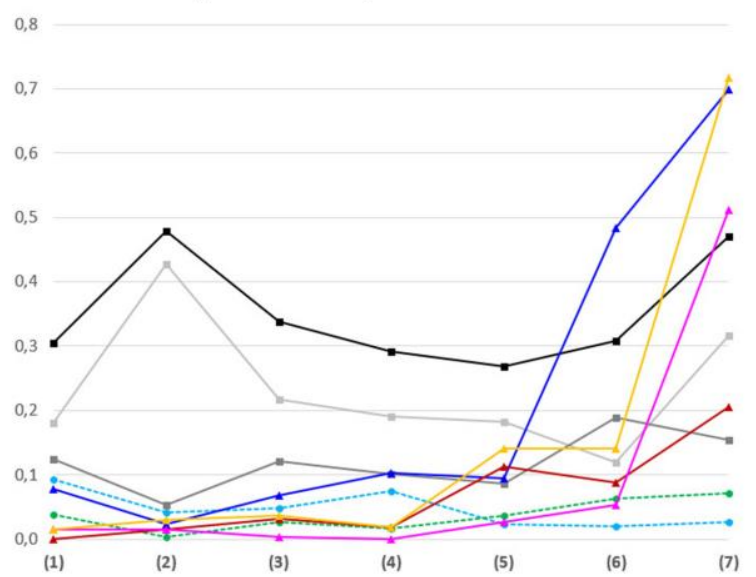

b) Atividades necessárias diurnas

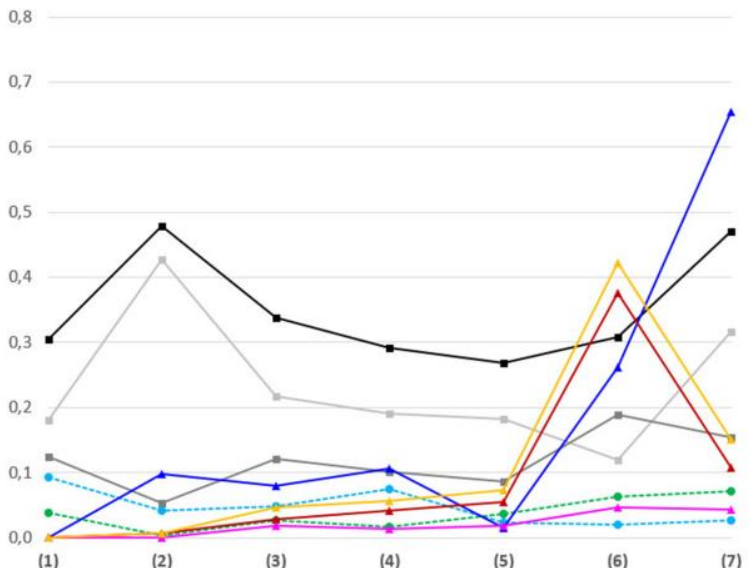

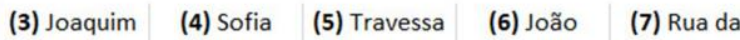

(1) Travessa dos (2) Leão XIII Nabuco Veloso do Carmo Alfredo República Taxas de permeabilidade

\begin{tabular}{|c|c|c|c|c|c|c|c|}
\hline \multicolumn{8}{|c|}{ Taxas de permeabilidade } \\
\hline Permeabilidade visual & 0,1811 & 0,4267 & 0,2171 & 0,1899 & 0,1828 & 0,1196 & 0,3160 \\
\hline Permeabilidade funcional & 0,1237 & 0,0528 & 0,1206 & 0,1019 & 0,0859 & 0,1882 & 0,1538 \\
\hline$\Sigma$ Taxas de permeabilidades & 0,3049 & 0,4794 & 0,3376 & 0,2918 & 0,2686 & 0,3078 & 0,4698 \\
\hline \multicolumn{8}{|c|}{ Taxas de usos } \\
\hline Uso residencial & 0,0927 & 0,0414 & 0,0485 & 0,0740 & 0,0225 & 0,0201 & 0,0268 \\
\hline Uso comercial e de serviço & 0,0386 & 0,0037 & 0,0269 & 0,0162 & 0,0361 & 0,0638 & 0,0708 \\
\hline \multicolumn{8}{|c|}{ a) Atividades opcionais diurnas } \\
\hline Em movimento & 0,0773 & 0,0226 & 0,0683 & 0,1022 & 0,0950 & 0,4831 & 0,6982 \\
\hline Estacionária em pé & 0,0000 & 0,0151 & 0,0324 & 0,0186 & 0,1131 & 0,0872 & 0,2051 \\
\hline Estacionária sentada & 0,0155 & 0,0151 & 0,0036 & 0,0000 & 0,0271 & 0,0537 & 0,5127 \\
\hline$\sum$ Estacionárias & 0,0155 & 0,0302 & 0,0360 & 0,0186 & 0,1402 & 0,1409 & 0,7177 \\
\hline \multicolumn{8}{|c|}{ b) Atividades necessárias diurnas } \\
\hline Em movimento & 0,0000 & 0,0980 & 0,0791 & 0,1068 & 0,0149 & 0,2617 & 0,6543 \\
\hline Estacionária em pé & 0,0000 & 0,0075 & 0,0288 & 0,0418 & 0,0543 & 0,3757 & 0,1074 \\
\hline Estacionária sentada & 0,0000 & 0,0000 & 0,0180 & 0,0139 & 0,0181 & 0,0470 & 0,0439 \\
\hline$\Sigma$ Estacionárias & 0,0000 & 0,0075 & 0,0468 & 0,0557 & 0,0724 & 0,4227 & 0,1514 \\
\hline
\end{tabular}

Tabela 3 - Correlações entre atividades nas quadras e taxas de permeabilidades e usos nos térreos (teste de Pearson)

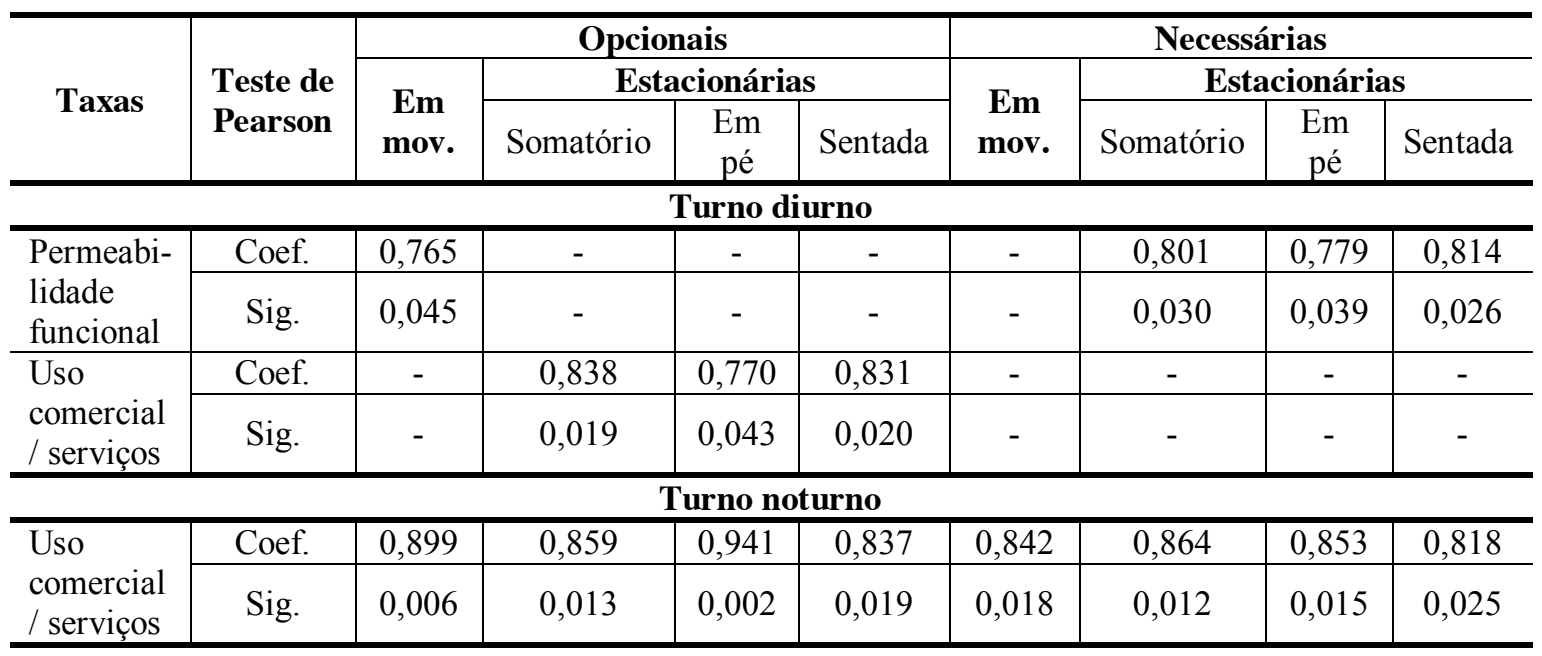

Nota: Legenda:

- inexistência de correlações; e mov. = movimento. 
Por outro lado, na quadra na Rua Leão XIII está a menor taxa de permeabilidade funcional $(0,0528$ - 5 acessos a cada $100 \mathrm{~m})$, refletindo a existência da menor taxa de edificações $(0,041 ; 4,1 \mathrm{em} 100 \mathrm{~m})$, embora as taxas de permeabilidade visual $(0,4267)$ e de permeabilidade visual e funcional somadas $(0,4794)$ sejam as maiores (Figura 5). Na quadra na Rua Joaquim Nabuco está a quarta maior taxa de permeabilidade funcional $(0,1206-12$ acessos a cada $100 \mathrm{~m})$, a terceira maior taxa de permeabilidade visual $(0,2171)$, e o quarto menor somatório das taxas de permeabilidade visual e funcional $(0,3376)$. Por sua vez, a Travessa dos Venezianos possui a terceira maior taxa de permeabilidade funcional $(0,1237$ - 12 acessos em $100 \mathrm{~m})$, a segunda menor taxa de permeabilidade visual $(0,1811)$ e a terceira menor soma da taxa de permeabilidade visual e funcional $(0,3049)$ (Figura 5).

\section{Atividades opcionais estacionárias}

A maior taxa de atividades opcionais estacionárias em pé diurnas está na quadra da Rua da República $(0,2051)$, seguida pela taxa na Travessa do Carmo $(0,1131)$, enquanto não foi observado tal tipo de atividade na Travessa dos Venezianos e quase não foi observada nas quadras na Rua Leão XIII $(0,0151)$ e na Rua Sofia Veloso (0,0186; Figuras 4a e 5). A maior taxa de atividades opcionais estacionárias sentadas também está na quadra na Rua da República $(0,5126)$, sendo muito maior que a segunda maior taxa $(0,0537)$ na quadra na Rua João Alfredo, não tendo sido observado esse tipo de atividade na Rua Sofia Veloso, e praticamente também não na quadra na Rua Joaquim Nabuco (0,0036). Assim, na quadra na Rua da República está a maior taxa de atividades opcionais estacionárias (em pé e sentadas somadas; 0,7177), muito maior do que o valor da segunda maior taxa $(0,1409)$, na quadra na Rua João Alfredo e da terceira maior taxa, na Travessa do Carmo $(0,1402)$, enquanto os menores valores estão na Travessa dos Venezianos $(0,0155)$ e na quadra na Rua Sofia Veloso $(0,0186)$ (Figura 5).

As taxas de atividades opcionais estacionárias diurnas somadas estão correlacionadas (Teste Pearson, Tabela 3) ao uso comercial/serviços nos térreos e, portanto, tendem a aumentar conforme aumenta a quantidade de térreos com comércio e serviços na quadra. Assim, considerando as quadras com as maiores taxas de atividades opcionais estacionárias em pé diurnas, verifica-se que a quadra na Rua da República possui uso predominantemente não residencial (35 un - 76,09\%) e uma taxa de uso comercial e de serviços $(0,0708)$ bem maior do que nas outras quadras (Tabela 1, Figura 5). Ainda, nessa quadra está a maior diversidade de usos nos térreos, registrando o segundo maior percentual de bares, restaurantes e cafeterias (13 un - 28,26\%) e o maior percentual de mercado/lojas ( 7 un $-15,22 \%$ ), atividades estas que tendem a ser atratores importantes de pessoas. Essa quadra também possui um conjunto de outros usos comerciais e de serviços (farmácia/lavanderia - 3 un - 6,52\%; cuidados com a saúde e o bem-estar - 3 un $-6,52 \%$; creche - 2 un $4,35 \%$; imobiliária/assessorias - 1 un - 2,17\%) e um uso residencial (11 un - 23,91\%) muito menor do que os usos comerciais e de serviços, e cuja taxa é a terceira menor $(0,0268)$ entre as sete quadras investigadas. Adicionalmente, essa quadra apresenta alto valor $(0,0708 / 0,0048=14,75)$ resultante da divisão entre a taxa de comércio e serviço e a taxa de térreos sem usos (Tabela 1). A Travessa do Carmo também tem uso predominantemente não residencial (23 un - 69,7\%) e a terceira maior taxa de uso comercial e de serviços $(0,0361)$. Embora apenas uma (1 un - 3,03\%) atividade nos térreos das edificações nesta travessa esteja na categoria bar/restaurante/cafeteria, há um conjunto de outras atividades que explicam a terceira maior taxa de uso comercial e de serviços $(0,0361)$, nomeadamente imobiliária/assessorias (4 un - 12,12\%); serviços partidários (3 un - 9,09\%); mercado/loja (2 un - 6,06\%); serviços comunitários e de lazer/turismo (2 un $6,06 \%)$; creche ( 1 un $-3,03 \%$ ); serviços de conserto e segurança ( 1 un - 3,03\%); espaço religioso (1 un $3,03 \%$ ); e serviços de tatuagem ( 1 un $-3,03 \%$ ). Ainda, existe um claro predomínio desses usos sobre o uso residencial (10 un -30,30\%), cuja taxa é a segunda menor $(0,0225)$ (Figura 5).

Com relação às quadras com as menores taxas de atividades opcionais estacionárias em pé diurnas, a Travessa dos Venezianos possui uso predominantemente residencial (12 un - 66,67\%), cuja taxa é a maior $(0,0927)$ entre as sete quadras (Tabela 1, Figura 5). Embora a Travessa dos Venezianos apresente a segunda maior taxa de uso comercial e de serviços $(0,0386)$ e possua o maior percentual de bares/restaurantes/cafeterias ( 5 un $-27,78 \%$ ), há pouca presença de pessoas durante o dia devido ao fato de os estabelecimentos abrirem suas portas no período da noite. A quadra na Rua Leão XIII possui quase que exclusivamente uso residencial dominante (11 un -91,67\%; taxa $=0,0414$ ), a menor taxa de uso comercial e de serviços (0,0037), e apenas uma atividade (1 un - 8,33\%) desse tipo (na categoria bar/restaurante/cafeteria). A quadra na Rua Sofia Veloso também possui o claro predomínio do uso residencial (32 un -82,05\%), cuja taxa é a segunda maior (0,0740), enquanto a taxa de usos comerciais e de serviços é a segunda menor $(0,0162)$, incluindo térreos com usos voltados para cuidados com a saúde e o 
bem-estar $(2-5,15 \%)$, e com os demais usos com uma única ocorrência cada (2,56\%): bar/restaurante/cafeteria, farmácia/lavanderia, creche, cuidados com pets e serviços de conserto e segurança.

Considerando as quadras com as maiores taxas de atividades opcionais estacionárias sentadas diurnas, além da quadra na Rua da República, a quadra na Rua João Alfredo possui visível predomínio de uso não residencial (30 un -83,33\%), com a menor taxa de uso residencial $(0,0201$; uso residencial em apenas 6 térreos - 16,22\%) (Tabela 1, Figura 5). Por outro lado, nessa quadra está a terceira menor taxa de uso comercial e de serviços $(0,0201)$, incluindo os seguintes usos nos térreos: bar/restaurante/cafeteria (3 un $8,11 \%$ ); creche ( 1 un $-2,70 \%$ ); serviços de conserto e segurança ( 1 un - 2,70\%); e espaço religioso ( 1 un $2,70 \%$ ). Essa pequena taxa se deve ao fato de que não foram considerados no cálculo os usos nos térreos de 14 casas noturnas, já que esses estabelecimentos estavam fechados nos horários de realização das observações de comportamento nessa quadra. Ainda, o fato de o valor resultante da relação entre as taxas de comércio e serviço e as taxas de térreos sem usos $(0,0201 / 0,0336=0,5982)$ ser menor do que 1 e bem menor que o da quadra na Rua da República $(14,75)$ indica que as atividades opcionais estacionárias sentadas diurnas nessa quadra têm pouca relação com os usos comerciais e serviços nos térreos.

Com relação às quadras com as menores taxas de atividades opcionais estacionárias sentadas diurnas, além daquela na Rua Sofia Veloso, a quadra na Rua Joaquim Nabuco possui uso não residencial (31 un - 53,45\%) um pouco superior ao uso residencial ( 27 un - 46,55\%), a quarta maior taxa de uso comercial e de serviços $(0,0269)$ e o terceiro maior percentual de bares, restaurantes e cafeterias ( 7 un $-12,07 \%$; com recuos e calçadas utilizados como áreas para mesas de restaurantes), embora este percentual seja bem menor do que nas quadras na Rua da República e na Travessa dos Venezianos (Tabela 1, Figura 5). Ainda, existem outros usos comerciais e de serviço na quadra na Rua Joaquim Nabuco, nomeadamente mercado/loja (3 un $5,17 \%$ ), imobiliária/assessorias ( 2 un $-3,45 \%$ ), cuidados com a saúde e o bem-estar ( 1 un $-1,72 \%$ ), cuidados com pets ( 1 un $-1,72 \%$ ) e espaço religioso ( 1 un $-1,72 \%)$. Portanto, esses usos comerciais e de serviços não tiveram efeito significativo na geração de atividades opcionais estacionárias sentadas diurnas.

\section{Atividades necessárias em movimento e estacionárias}

Visivelmente, a maior taxa de atividades necessárias em movimento diurnas está na quadra na Rua da República $(0,6543)$, seguida pela taxa na quadra na Rua João Alfredo $(0,2617)$, enquanto não existe tal atividade na Travessa dos Venezianos e quase não existe na Travessa do Carmo $(0,0149)$ (Figura 5). Por sua vez, a maior taxa de atividades necessárias estacionárias em pé diurnas está na quadra na Rua João Alfredo $(0,3757)$ seguida da taxa na Rua da República $(0,1074)$, não tendo sido observada tal tipo de atividade na Travessa dos Venezianos e, basicamente, também não na quadra na Rua Leão XIII $(0,0075)$. Adicionalmente, as duas maiores taxas de atividades necessárias estacionárias sentadas diurnas são muito próximas e estão nas quadras na Rua João Alfredo $(0,0470)$ e na Rua da República $(0,0439)$, não tendo sido observado esse tipo de atividade na Travessa dos Venezianos (Figura 5).

Logo, na quadra na Rua João Alfredo está a maior taxa de atividades necessárias estacionárias (em pé e sentadas somadas; 0,4227$)$, seguida pela taxa na quadra na Rua da República $(0,1514)$, enquanto esse tipo de atividade não foi observado na Travessa dos Venezianos e praticamente não foi observado na quadra na Rua Leão XIII $(0,0075)$ (Figura 5). As taxas de atividades necessárias estacionárias somadas, em pé e sentadas diurnas, estão correlacionadas à taxa de permeabilidade funcional (teste de Pearson, Tabela 3) e, logo, tendem a aumentar à medida que essa taxa aumenta.

\section{Totais de atividades diurnas na quadra}

Considerando a soma de todas as atividades diurnas (opcionais em movimento e estacionárias + necessárias em movimento e estacionárias) observadas, a quadra na Rua da República é aquela com a maior taxa $(2,2215=222$ pessoas em $100 \mathrm{~m})$, quase o dobro da segunda maior taxa $(1,3083$; quadra na Rua João Alfredo), e quase sete vezes a terceira maior taxa (0,3225; Travessa do Carmo) (Figura 6). Por outro lado, a Travessa dos Venezianos possui a menor taxa $(0,0928)$, seguida pela taxa na quadra da Rua Leão XIII $(0,1583)$ (Figura 6). 


\section{Figura 6 - Taxas do total de atividades observadas no período do dia em cada quadra}

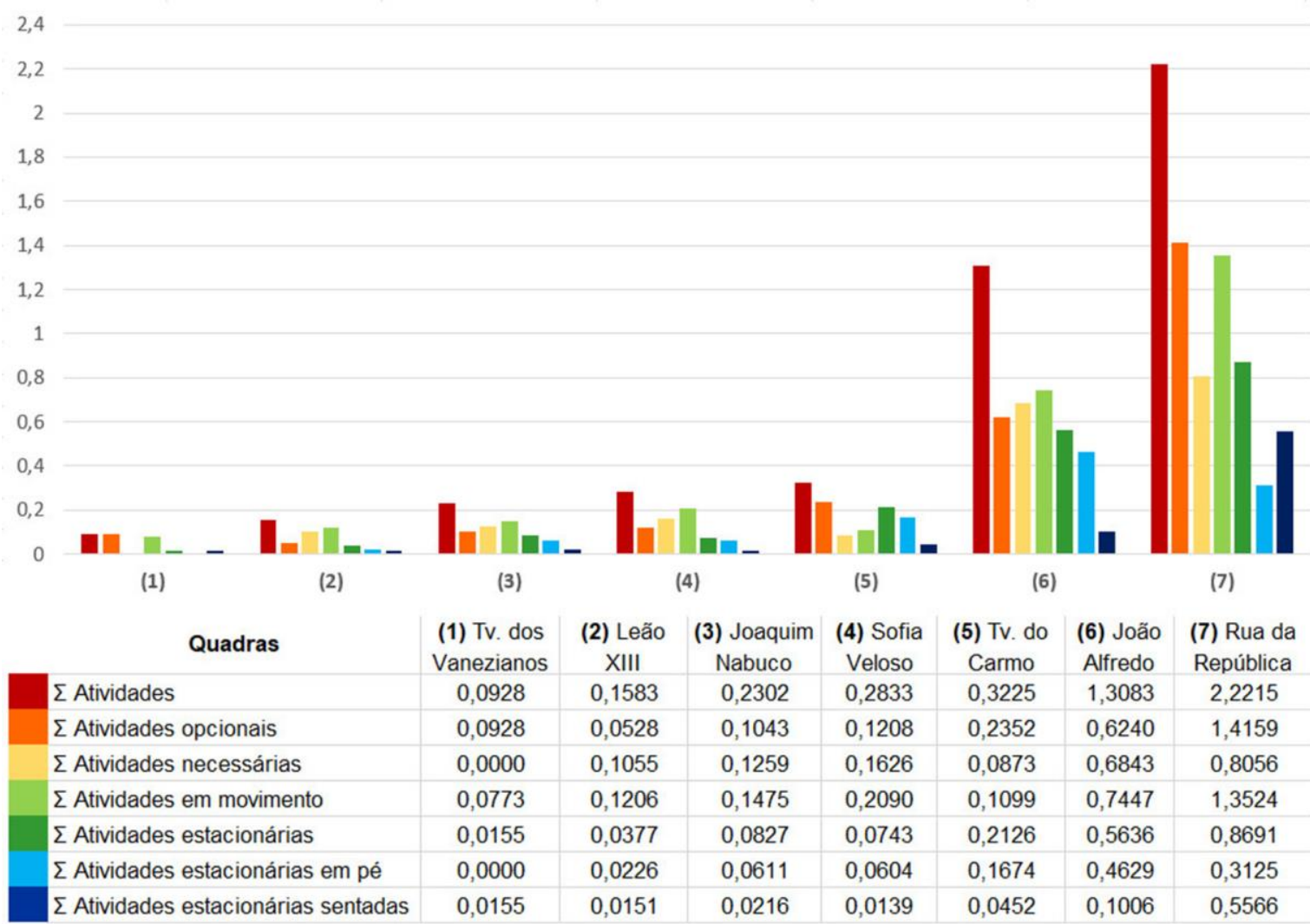

Comparando as taxas de atividades diurnas observadas (das $12 \mathrm{~h} 30$ até as $14 \mathrm{~h}$ ) com o uso da quadra pelo morador no período das $12 \mathrm{~h}$ até as $14 \mathrm{~h}$, verifica-se que a quadra Rua da República (aquela com a maior taxa) possui apenas o quarto maior uso pelos moradores, enquanto aquelas com o maior trânsito de moradores (Travessa do Carmo e Rua Leão XIII) possuem respectivamente a terceira maior e a segunda menor taxa de atividades diurnas observadas (Figuras 6 e 7). Ainda, há uma relação estatisticamente significativa $($ Phi = 0,295 ; sig. $=0,010$ ) entre o uso da quadra depois das $12 \mathrm{~h}$ e até as $14 \mathrm{~h}$ e a quadra onde o respondente mora, com o maior trânsito pelos moradores ocorrendo na Travessa do Carmo (62,5\% - 20 de 30), seguida pela Rua Leão XIII (45,5\% - 15 de 33) e Rua João Alfredo (40\% - 12 de 30) (Figura 7). Por outro lado, não existe uso da quadra nesse período por moradores da Travessa dos Venezianos, havendo pouco uso pelos moradores na Rua Joaquim Nabuco (23,3\% - 7 de 30) e na Rua Sofia Veloso (25\% - 8 de 32) (Figura 7). Logo, os moradores da Rua da República utilizam menos sua quadra nesse período do que os moradores de outras três quadras, o que indica que parte expressiva do uso na Rua da República em tal período é explicado pela presença de visitantes.

Com relação ao somatório das atividades opcionais (em movimento e estacionárias) diurnas, a maior taxa está na quadra na Rua da República (1,4159), seguida pela taxa na quadra na Rua João Alfredo $(0,6240)$, enquanto a menor está na quadra na Rua Leão XIII (0,0528), seguida pela taxa na Travessa dos Venezianos $(0,0928)$ (Figura 6). Da mesma forma, está na Rua da República $(0,8056)$ a maior taxa de atividade necessária (em movimento e estacionárias somadas) diurna, seguida pela taxa na Rua João Alfredo $(0,6843)$, não tendo sido observadas tais atividades na Travessa dos Venezianos, e poucas foram observadas na Travessa do Carmo (0,0873), na Rua Leão XIII $(0,1055)$, e na Rua Joaquim Nabuco $(0,1259)$. Também está na quadra da Rua da República a maior taxa de atividades em movimento (opcionais e necessárias somadas) diurnas (1,3524), quase o dobro da segunda maior taxa, na Rua João Alfredo (0,7447). Por outro lado, a menor taxa está na Travessa dos Venezianos $(0,0773)$, seguida pela taxa na Travessa do Carmo $(0,1099)$ e na Rua Leão XIII (0,1206) (Figura 6).

Novamente, na quadra na Rua da República está a maior taxa de atividades estacionárias (opcionais e necessárias somadas; 0,8691) diurnas, seguida pela taxa na Rua João Alfredo $(0,5636)$ e na Travessa do Carmo $(0,2126)$, enquanto as demais são bem menores, com a menor taxa na Travessa dos Venezianos $(0,0155)$, seguida pela taxa na Rua Leão XIII $(0,0377)$ (Figura 6). Com relação ao somatório das atividades 
estacionárias em pé (opcionais + necessárias) diurnas, está na João Alfredo a maior taxa (0,4629), seguida pelas taxas na Rua da República $(0,3125)$ e na Travessa do Carmo $(0,1674)$. Por outro lado, não existe esse tipo de atividade na Travessa dos Venezianos e quase não existe na Rua Leão XIII (0,0226). Além disso, na quadra na Rua da República também está a maior taxa de atividades estacionárias sentadas (opcionais e necessárias somadas) diurnas $(0,5566)$, quase seis vezes a segunda maior taxa $(0,1006$ na Rua João Alfredo), estando na Rua Sofia Veloso a menor taxa $(0,0139)$, seguida pelas taxas na Rua Leão XIII $(0,0151)$ e na Travessa dos Venezianos $(0,0155)$ (Figura 6).

\section{Atividades noturnas: edificações com diferentes recuos frontais, níveis de permeabilidade e usos}

\section{Atividades opcionais em movimento}

Claramente, a maior taxa de atividades opcionais em movimento noturnas está na quadra na Rua da República (0,8349; Figura 3b), seguida pela quadra na Rua João Alfredo $(0,1879)$, enquanto a menor está na quadra na Rua Leão XIII (0,0151), seguida pelas taxas na quadra na Rua Sofia Veloso $(0,1393$; Figura 4b) e na Travessa dos Venezianos $(0,1546)$ (Figura 8).

\section{Atividades opcionais estacionárias}

A maior taxa de atividades opcionais estacionárias em pé noturnas está na quadra na Rua da República $(0,3174)$, seguida pela taxa na Travessa dos Venezianos $(0,2010)$, enquanto a menor está na quadra na Rua Sofia Veloso $(0,0418)$, seguida pelas taxas nas quadras na Rua Leão XIII $(0,0829)$ e na Rua João Alfredo $(0,0872)$ (Figura 8).

Figura 7 - Turnos em que o morador mais transita na quadra onde mora

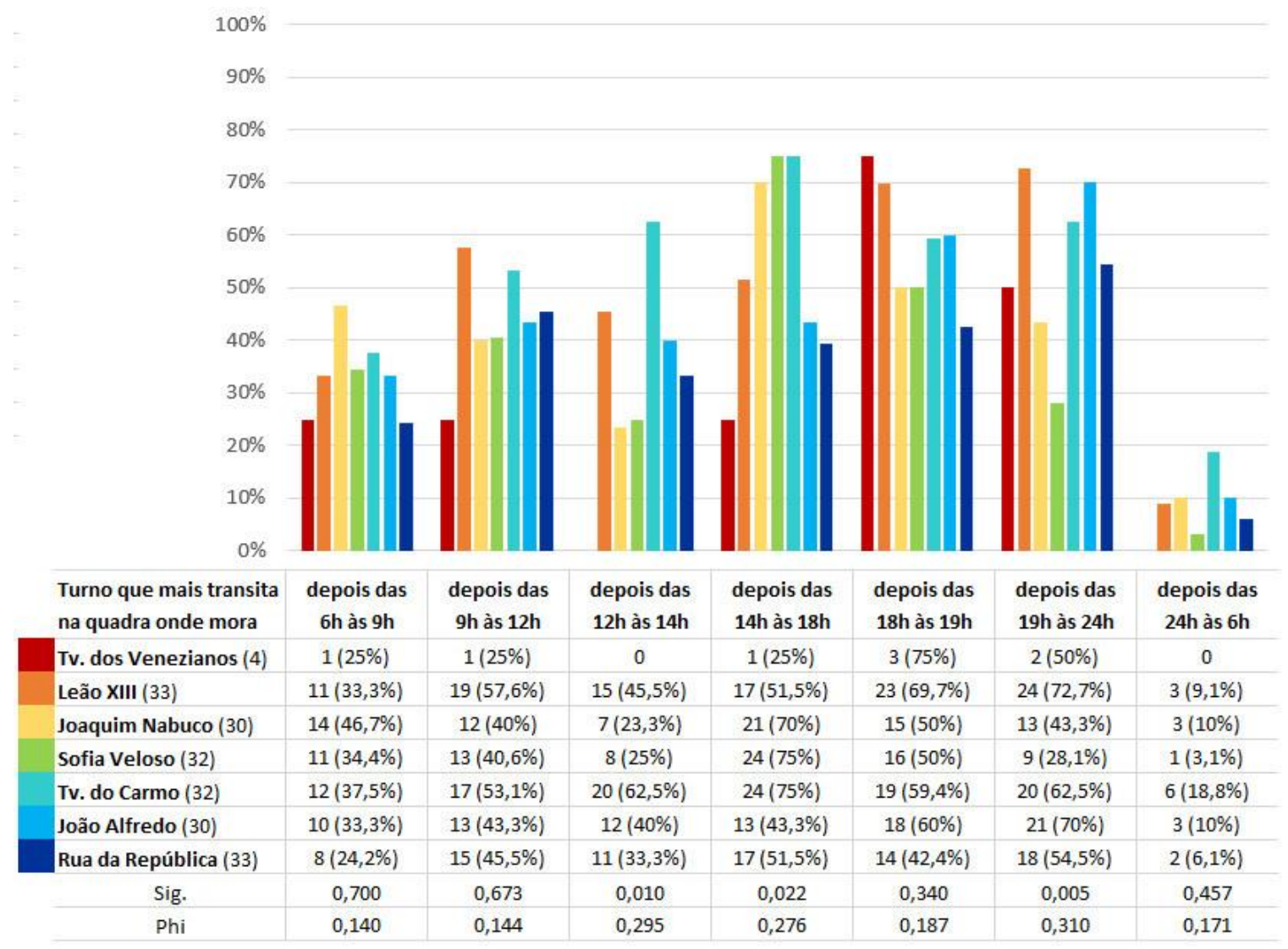


Figura 8 - Taxas de atividades opcionais e necessárias noturnas nas quadras, níveis de permeabilidade e usos nos térreos
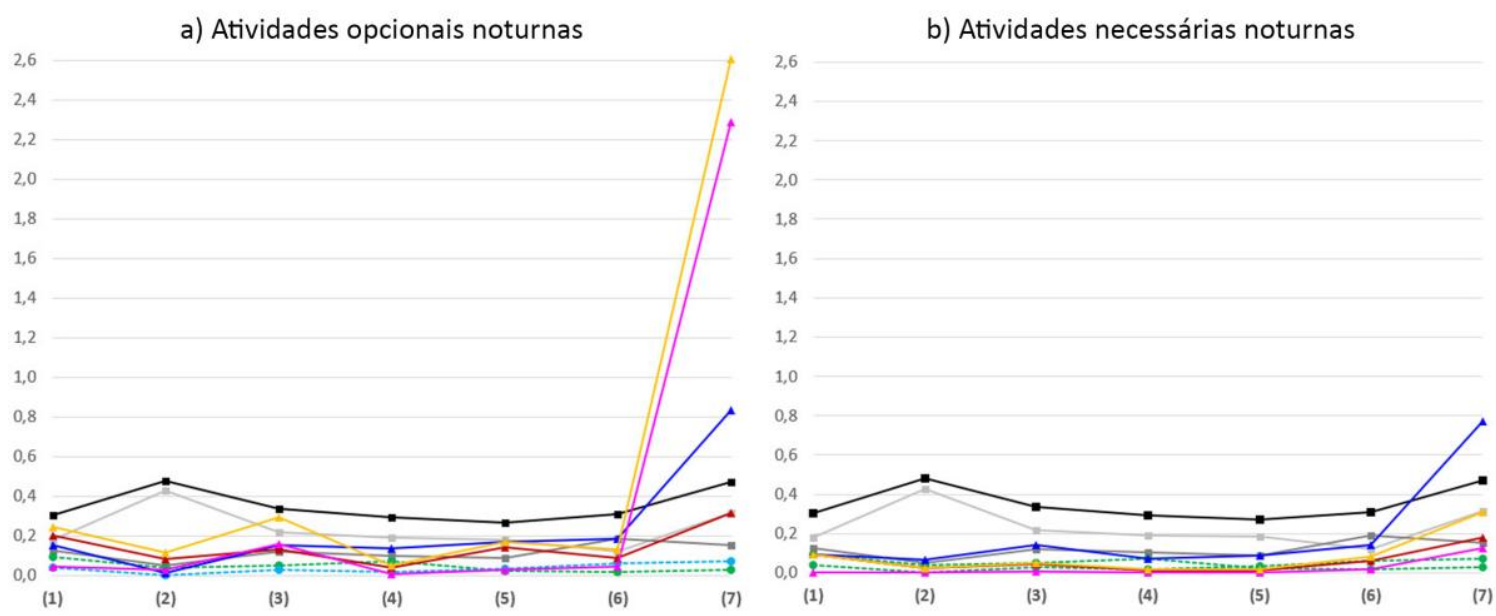

\begin{tabular}{|c|c|c|c|c|c|c|c|c|}
\hline & Legenda & $\begin{array}{c}\text { (1) Travessa } \\
\text { dos Venezianos }\end{array}$ & (2) Leão XIII & $\begin{array}{l}\text { (3) Joaquim } \\
\text { Nabuco }\end{array}$ & $\begin{array}{l}\text { (4) Sofia } \\
\text { Veloso }\end{array}$ & $\begin{array}{l}\text { (5) Travessa } \\
\text { do Carmo }\end{array}$ & $\begin{array}{l}\text { (6) João } \\
\text { Alfredo }\end{array}$ & $\begin{array}{l}\text { (7) Rua da } \\
\text { República }\end{array}$ \\
\hline \multicolumn{9}{|c|}{ Taxas de permeabilidade } \\
\hline$\rightarrow$ & Permeabilidade visual & 0,1811 & 0,4267 & 0,2171 & 0,1899 & 0,1828 & 0,1196 & 0,3160 \\
\hline$\rightarrow-$ & Permeabilidade funcional & 0,1237 & 0,0528 & 0,1206 & 0,1019 & 0,0859 & 0,1882 & 0,1538 \\
\hline$\rightarrow$ & $\Sigma$ Taxas de permeabilidades & 0,3049 & 0,4794 & 0,3376 & 0,2918 & 0,2686 & 0,3078 & 0,4698 \\
\hline \multicolumn{9}{|c|}{ Taxas de usos } \\
\hline$\cdots \bullet$ & Uso residencial & 0,0927 & 0,0414 & 0,0485 & 0,0740 & 0,0225 & 0,0201 & 0,0268 \\
\hline -.. & Uso comercial e de serviço & 0,0386 & 0,0037 & 0,0269 & 0,0162 & 0,0361 & 0,0638 & 0,0708 \\
\hline \multicolumn{9}{|c|}{ a) Atividades opcionais noturnas } \\
\hline 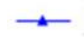 & Em movimento & 0,1546 & 0,0151 & 0,1546 & 0,1393 & 0,1719 & 0,1879 & 0,8349 \\
\hline$\rightarrow$ & Estacionária em pé & 0,2010 & 0,0829 & 0,1331 & 0,0418 & 0,1402 & 0,0872 & 0,3174 \\
\hline$\rightarrow$ & Estacionária sentada & 0,0464 & 0,0302 & 0,1582 & 0,0093 & 0,0317 & 0,0470 & 2,2899 \\
\hline & $\sum$ Estacionárias & 0,2474 & 0,1131 & 0,2913 & 0,0511 & 0,1719 & 0,1342 & 2,6072 \\
\hline \multicolumn{9}{|c|}{ b) Atividades necessárias noturnas } \\
\hline$\rightarrow$ & Em movimento & 0,0928 & 0,0679 & 0,1403 & 0,0743 & 0,0860 & 0,1409 & 0,7714 \\
\hline$\longleftarrow$ & Estacionária em pé & 0,0928 & 0,0226 & 0,0432 & 0,0139 & 0,0136 & 0,0604 & 0,1807 \\
\hline- & Estacionária sentada & 0,0000 & 0,0000 & 0,0072 & 0,0046 & 0,0045 & 0,0201 & 0,1269 \\
\hline & $\sum$ Estacionárias & 0,0928 & 0,0226 & 0,0504 & 0,0186 & 0,0181 & 0,0805 & 0,3076 \\
\hline
\end{tabular}

A maior taxa de atividades opcionais estacionárias sentadas também está na quadra na Rua da República $(2,2899)$, sendo muito maior que a segunda maior taxa $(0,1582)$ na Rua Joaquim Nabuco, enquanto a menor está na quadra na Rua Sofia Veloso $(0,0093)$, seguida pelas taxas na quadra na Rua Leão XIII $(0,0302)$ e na Travessa do Carmo $(0,0317)$ (Figura 8).

Assim, na quadra na Rua da República está a maior taxa de atividades opcionais estacionárias (em pé e sentadas somadas; 2,6072), muito maior do que o valor da segunda maior taxa $(0,2913)$, na quadra na Rua Joaquim Nabuco e da terceira maior taxa na Travessa dos Venezianos $(0,2474)$, enquanto os menores valores estão nas quadras na Rua Sofia Veloso $(0,0511)$ e na Rua Leão XIII $(0,1131)$ (Figura 8).

\section{Atividades necessárias em movimento e estacionárias}

Nitidamente, a maior taxa de atividades necessárias em movimento noturnas está na quadra na Rua da República $(0,7714)$, seguida pela quadra na Rua João Alfredo $(0,1409)$, enquanto a menor está na quadra na Rua Leão XIII $(0,0679)$, seguida pelas taxas na quadra na Rua Sofia Veloso $(0,0743)$ e na Travessa do Carmo $(0,0860)$ (Figura 8).

A maior taxa de atividades necessárias estacionárias em pé noturnas está na quadra na Rua da República $(0,1807)$, seguida pela taxa na Travessa dos Venezianos $(0,0928)$, enquanto a menor está na Travessa do Carmo $(0,0136)$, seguida pelas taxas nas quadras na Rua Sofia Veloso $(0,0139)$ e na Rua Leão XIII $(0,0226)$ (Figura 8). A maior taxa de atividades necessárias estacionárias sentadas também está na quadra na Rua da República $(0,1269)$, sendo muito maior que a segunda maior taxa $(0,02013)$, na quadra na Rua João Alfredo, 
não tendo sido observado esse tipo de atividade na Rua Leão XIII e na Travessa dos Venezianos e praticamente também não na Travessa do Carmo $(0,0045)$ e na quadra na Rua Sofia Veloso $(0,0046)$ (Figura 8).

Assim, na quadra na Rua da República está a maior taxa de atividades necessárias estacionárias (em pé e sentadas somadas; 0,3076), muito maior do que o valor da segunda maior taxa $(0,0928)$, na Travessa dos Venezianos e da terceira maior taxa, na quadra na Rua João Alfredo $(0,0805)$, enquanto os menores valores estão na Travessa do Carmo (0,0181) e na Rua Sofia Veloso (0,0186) (Figura 8). Ainda, as taxas de atividades opcionais (em movimento e estacionárias) e necessárias (em movimento e estacionárias) noturnas estão correlacionadas (teste de Pearson; Tabela 3) à taxa de uso comercial e de serviços nos térreos das edificações, e, logo, tendem a aumentar à medida que essa taxa aumenta.

\section{Totais de atividades noturnas na quadra}

Considerando todas as atividades noturnas (opcionais em movimento e estacionárias, e necessárias em movimento e estacionárias somadas) observadas, a maior taxa está na quadra na Rua da República $(4,5212)$, sete vezes a segunda maior taxa $(0,6366$ na Joaquim Nabuco), seguida pelas taxas na Travessa dos Venezianos $(0,5876)$ e na Rua João Alfredo $(0,5434)$. Por outro lado, a menor taxa está na quadra da Rua Leão XIII $(0,2186)$, seguida pela taxa na Rua Sofia Veloso $(0,2833)$ (Figura 9).

Comparando as taxas de atividades noturnas observadas (das $18 \mathrm{~h} 30$ até as $20 \mathrm{~h}$ ) com o uso da quadra pelo morador nos períodos depois das $18 \mathrm{~h}$ e até as $19 \mathrm{~h}$ e depois das $19 \mathrm{~h}$ e até as $00 \mathrm{~h}$, verifica-se que a quadra na Rua da República (aquela com a taxa bem maior que as demais quadras) possui apenas o sétimo (depois das $18 \mathrm{~h}$ e até as $19 \mathrm{~h}$ ) e o quarto (depois das $19 \mathrm{~h}$ e até as $00 \mathrm{~h}$ ) maior uso pelos moradores, e a Rua Joaquim Nabuco (aquela com a segunda maior taxa) possui apenas o quinto (depois das $18 \mathrm{~h}$ e até as $19 \mathrm{~h}$ ) e o sexto (depois das $19 \mathrm{~h}$ e até as 00h) maior uso pelos moradores (Figura 7). Por sua vez, as quadras na Travessa dos Venezianos (terceira maior taxa) e na Rua Leão XIII (menor taxa) possuem o maior uso (depois das $18 \mathrm{~h}$ e até as 19h), e a Leão XIII tem o maior uso pelos moradores depois das $19 \mathrm{~h}$ e até as $00 \mathrm{~h}$.

\section{Figura 9 - Taxas do somatório das atividades observadas no período da noite em cada quadra}

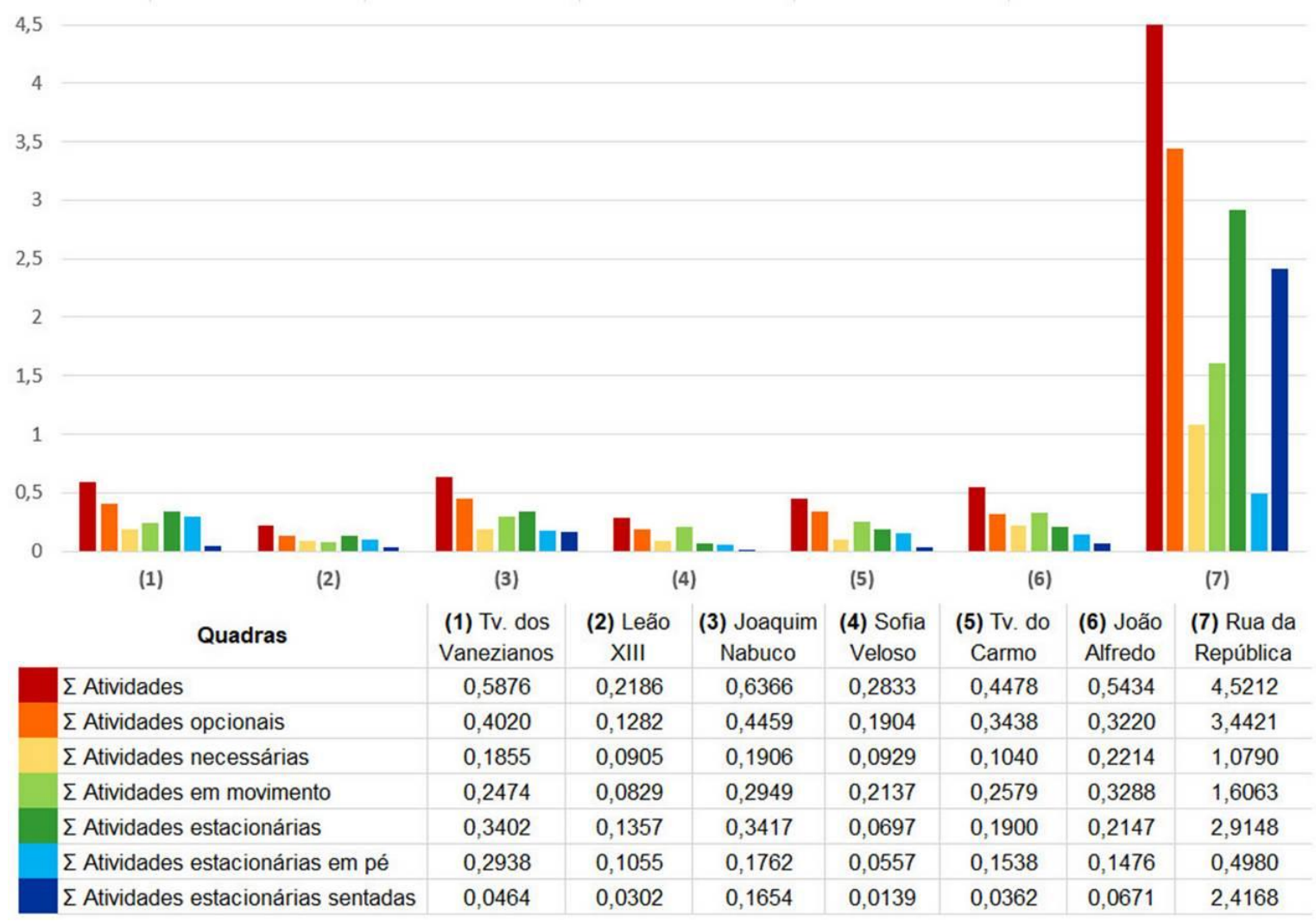

Atividades nos espaços abertos públicos: edificações com diferentes recuos frontais, níveis de permeabilidade e usos 63 
Ainda, existe relação estatisticamente significativa (Phi $=0,310 ; \mathrm{sig} .=0,005)$ entre o uso da quadra depois das $19 \mathrm{~h}$ e até as $24 \mathrm{~h}$ e a quadra onde o respondente mora, com o maior trânsito pelos moradores ocorrendo na Rua Leão XIII (72,7\% - 24 de 33), seguida pela Rua João Alfredo (70\% - 21 de 30) e pela Travessa do Carmo (62,5\% - 20 de 32), e a quadra Rua da República (56,3\% - 18 de 33), enquanto o menor trânsito é na Rua Sofia Veloso (30\% - 9 de 32) (Figura 7). Esses resultados revelam que os moradores da quadra na Rua da República utilizam menos sua quadra nesse período do que os moradores de outras três quadras, o que indica que parte expressiva do uso na Rua da República é explicado pela presença de visitantes.

Por sua vez, a maior taxa de atividades opcionais (em movimento e estacionárias somadas) noturnas também está na Rua da República (3,4421), quase oito vezes a segunda maior taxa (0,4459), na Rua Joaquim Nabuco, seguida pela Travessa dos Venezianos $(0,4020)$, ao passo que a menor está na Rua Leão XIII $(0,1282)$, seguida pela taxa na Rua Sofia Veloso $(0,1904)$ (Figura 9). Adicionalmente, está na Rua da República a maior taxa de atividades necessárias (em movimento e estacionárias somadas) noturnas $(1,0790)$, quase cinco vezes a segunda maior taxa (0,2214), na Rua João Alfredo, seguida pelas taxas na Rua Joaquim Nabuco $(0,1906)$ e na Travessa dos Venezianos $(0,1855)$. Por outro lado, as menores taxas estão na Rua Leão XIII (0,0905), na Rua Sofia Veloso (0,0929) e na Travessa do Carmo (0,1040) (Figura 9).

Igualmente, está na quadra na Rua da República a maior taxa de atividades em movimento (opcionais e necessárias somadas) noturnas $(1,6063)$, sendo quase cinco vezes a segunda maior taxa $(0,3288)$, na Rua João Alfredo, enquanto na Rua Leão XIII está a menor taxa $(0,0829)$, seguida pela taxa na Rua Sofia Veloso $(0,2137)$ (Figura 9).

A maior taxa de atividades estacionárias (opcionais + necessárias) também está na quadra na Rua da República (2,9148), quase nove vezes a segunda maior taxa $(0,3417)$, na Rua Joaquim Nabuco, seguida pela taxa na Travessa dos Venezianos $(0,3402)$. Na Rua Sofia Veloso está visivelmente a menor taxa $(0,0697)$, seguida por aquela na Rua Leão XIII $(0,1357)$ (Figura 9). Ainda, está na Rua da República a maior taxa de atividades estacionárias (opcionais + necessárias) em pé $(0,4980)$, seguida pela taxa na Travessa dos Venezianos $(0,2938)$, enquanto a menor está na Rua Sofia Veloso $(0,0557)$, seguida por aquela na Rua Leão XIII (0,1055) (Figura 9). Adicionalmente, a taxa de atividades estacionárias (opcionais + necessárias) sentadas na quadra na Rua da República $(2,4168)$ é quase quinze vezes a segunda maior taxa $(0,1654)$, na Rua Joaquim Nabuco, com a menor taxa na Rua Sofia Veloso $(0,0139)$, seguida pelas taxas na Rua Leão XIII $(0,0302)$, na Travessa do Carmo $(0,0362)$ e na Travessa dos Venezianos $(0,0464)$ (Figura 9).

\section{Total de atividades nas quadras}

Considerando o total de atividades na quadra (atividades diurnas e noturnas somadas), a taxa na Rua da República $(6,7427)$ é quase quatro vezes a segunda maior taxa $(1,8517)$, na Rua João Alfredo, seguida pelas taxas na Rua Joaquim Nabuco $(0,8667)$ e na Travessa do Carmo $(0,7704)$. Por outro lado, a menor taxa está na Rua Leão XIII $(0,3769)$, seguida pela Rua Sofia Veloso $(0,5666)$ e pela Travessa dos Venezianos $(0,6803)$ (Figura 10).

Considerando o total de atividades opcionais (diurnas + noturnas), a maior taxa está na quadra na Rua da República $(4,8581)$, cinco vezes a segunda maior taxa $(0,9460)$, na Rua João Alfredo, seguida pelas taxas na Travessa do Carmo $(0,5790)$ e na Rua Joaquim Nabuco $(0,5502)$ (Figura 10). Por outro lado, a menor taxa está na Rua Leão XIII $(0,1809)$, seguida pela taxa na Rua Sofia Veloso $(0,3112)$. A maior taxa de atividades necessárias (diurnas + noturnas) também está na quadra na Rua da República $(1,8846)$, seguida pela taxa na Rua João Alfredo $(0,9057)$, enquanto a menor está na Travessa dos Venezianos $(0,1855)$, seguida pelas taxas na Travessa do Carmo (0,1913), na Rua Leão XIII (0,1960) e na Rua Sofia Veloso (0,2554) (Figura 10).

Comparando as taxas de atividades opcionais e atividades opcionais realizadas pelos moradores, verifica-se similaridade entre as intensidades dessas atividades, com exceção da quadra na Rua Joaquim Nabuco (220\% - $1^{\text {o }}$; quarta maior taxa), onde está o maior somatório $(220 \%)$ de atividades opcionais indicadas pelos moradores da quadra e somente a quarta maior taxa de atividades opcionais (Figura 11). Assim, as outras quadras mais utilizadas pelos moradores para atividades opcionais também são aquelas com as maiores taxas de atividades opcionais, nomeadamente aquelas na Rua da República $\left(212,2 \%-2^{\circ}\right.$; maior taxa), na Rua João Alfredo (206,6\% - 3 ${ }^{\circ}$; segunda maior taxa) e na Travessa do Carmo (200,1\% - $4^{\mathrm{o}}$; terceira maior taxa), enquanto aquelas menos utilizadas pelos moradores também são aquelas com as menores taxas de atividades opcionais, especificamente a Rua Sofia Veloso (156,3\% - $7^{\circ}$; sexta maior taxa), a Travessa dos Venezianos $\left(175 \%-6^{\circ}\right.$; quinta maior taxa) e a Rua Leão XIII (193,4\% - 5\% ; menor taxa). Logo, os atributos das quadras que atraem os visitantes para atividades opcionais também tendem a atrair seus moradores (Figura 11). 
Figura 10 - Taxas do somatório das atividades observadas em ambos os períodos em cada quadra

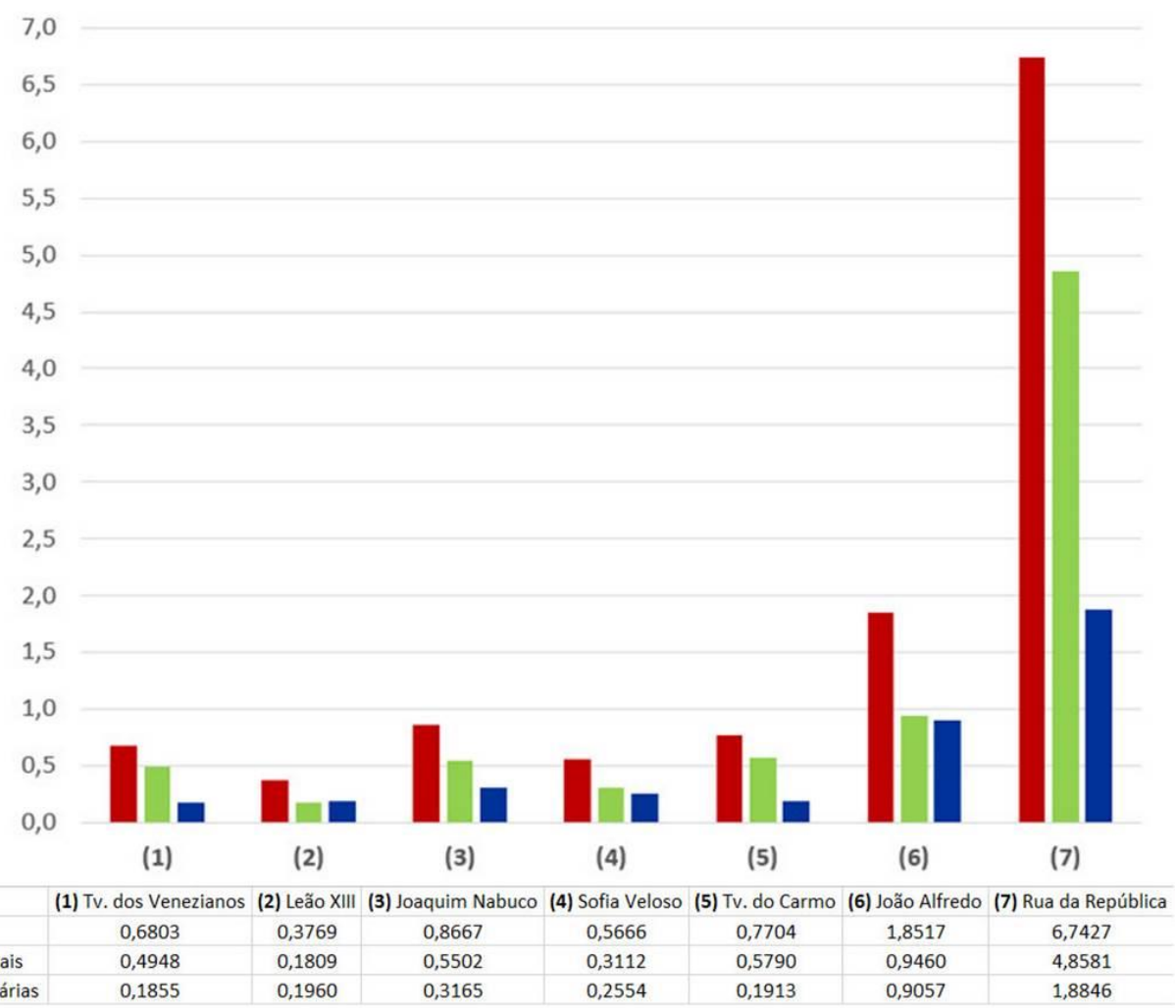

Figura 11 - Atividades necessárias e opcionais realizadas nas quadras pelos moradores

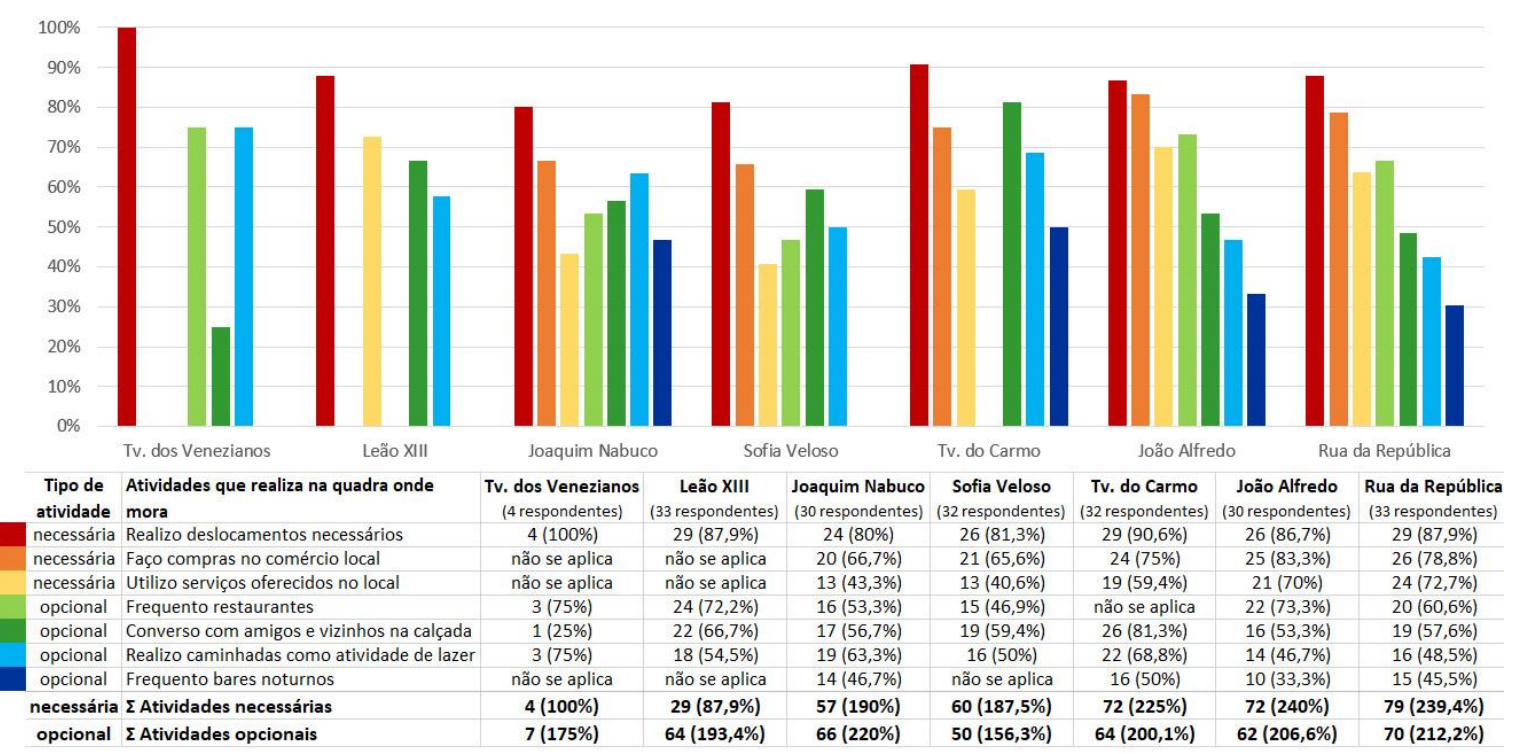

Adicionalmente, existe similaridade entre as taxas de atividades necessárias e as atividades necessárias realizadas pelos moradores, com exceção da quadra na Travessa do Carmo (225\% - 3\% ; $6^{\circ}$ maior; Figura 11), onde está o terceiro maior somatório de atividades necessárias indicadas pelos moradores da quadra e somente a sexta maior taxa de atividades necessárias (Figura 9). Assim, as demais quadras mais utilizadas pelos moradores para atividades necessárias também são aquelas com as maiores taxas de atividades necessárias, nomeadamente aquelas na Rua João Alfredo (240\% $-1^{\text {o}}$; segunda maior taxa), na Rua da República $\left(239,4 \%-2^{\text {o}}\right.$; maior taxa) e na Joaquim Nabuco (190\% - 4 ; terceira maior taxa), enquanto aquelas menos utilizadas pelos moradores para atividades necessárias também são aquelas com as menores 
taxas de atividades necessárias, especificamente, Rua Leão XIII (87,9\% - $7^{\circ}$; quinta maior), Travessa dos Venezianos (100\% - 6 $6^{\text {; }}$ menor taxa) e Rua Sofia Veloso (187,5\% - 5 ; quarta maior) (Figura 11). Portanto, os usos nos térreos das edificações por comércios e serviços necessários auxiliam na presença de pessoas nas quadras, não somente de visitantes, mas também de seus moradores. Adicionalmente, esses resultados evidenciam que os períodos de realização das observações foram adequados para captar as principais atividades opcionais e necessárias nas quadras.

\section{Escolha em transitar ou frequentar a quadra caso não morasse nela: atividades na quadra, edificações com diferentes recuos frontais, níveis de permeabilidade e usos}

Os maiores números de moradores que escolheram transitar por suas quadras caso não morassem nelas estão na Rua Joaquim Nabuco (73,3\%) e na Rua da República (72,7\%), enquanto os menores estão na Rua João Alfredo (33,3\%) e na Rua Leão XIII (45,5\%) (Figura 12). As principais justificativas indicadas pelos moradores destas duas quadras revelam a importância da presença de comércio e serviço (Joaquim Nabuco 72,7\%; Rua da República - 75\%), assim como da presença de pessoas (Joaquim Nabuco - 59,1\%; Rua da República - 83,3\%), aspectos diretamente relacionados aos usos dos térreos (Figura 12). Ainda, a arborização (facilitada pela largura da calçada, assim como pela existência de recuos) é uma justificativa relevante (Joaquim Nabuco - 50\%; Rua da República - 79,2\%), assim como a própria largura adequada da calçada (Joaquim Nabuco - 45,5\%; Rua da República - 58,3\%), variando entre $4 \mathrm{~m}$ e 4,60 m na quadra na Rua Joaquim Nabuco e entre 4,5 m e 6,60 m na Rua da República. Por sua vez, a indicação bem mais expressiva da distância agradável entre os prédios e a calçada pelos moradores da quadra na Rua da República $(54,2 \%)$ do que na quadra na Rua Joaquim Nabuco $(31,8 \%)$ reflete o fato de essa quadra possuir apenas $39,86 \%(221,5 \mathrm{~m})$ das interfaces alinhadas junto à calçada e de a quadra na Rua da República possuir $92,36 \%(378,22 \mathrm{~m})$ das interfaces alinhadas, e, logo, do fato de essa quadra ser mais atraente para os pedestres (Figura 12).

Por outro lado, os maiores números de moradores que escolheram não transitar por suas quadras caso não morassem nelas estão na Rua João Alfredo (66,7\%) e na Rua Leão XIII (54,5\%), fundamentalmente em razão da falta de segurança (João Alfredo - 80\%; Leão XIII - 61,1\%) (Figura 13), possivelmente em função: da Rua Leão XIII ser sem saída e possuir taxas de atividades, assim como aquelas realizadas pelos moradores, tanto opcionais quanto necessárias, que estão entre as mais baixas; da atração na quadra da Rua João Alfredo de muitos visitantes pelos bares que abrem a partir das $22 \mathrm{~h}$, e de pessoas bebendo na rua mesmo antes desse horário, o que é suportado pela indicação da "presença de pessoas transitando" por 30\% daqueles moradores que não desejam transitar nessa quadra.

Figura 12 - Justificativas para a escolha de transitar na quadra caso não morasse nela

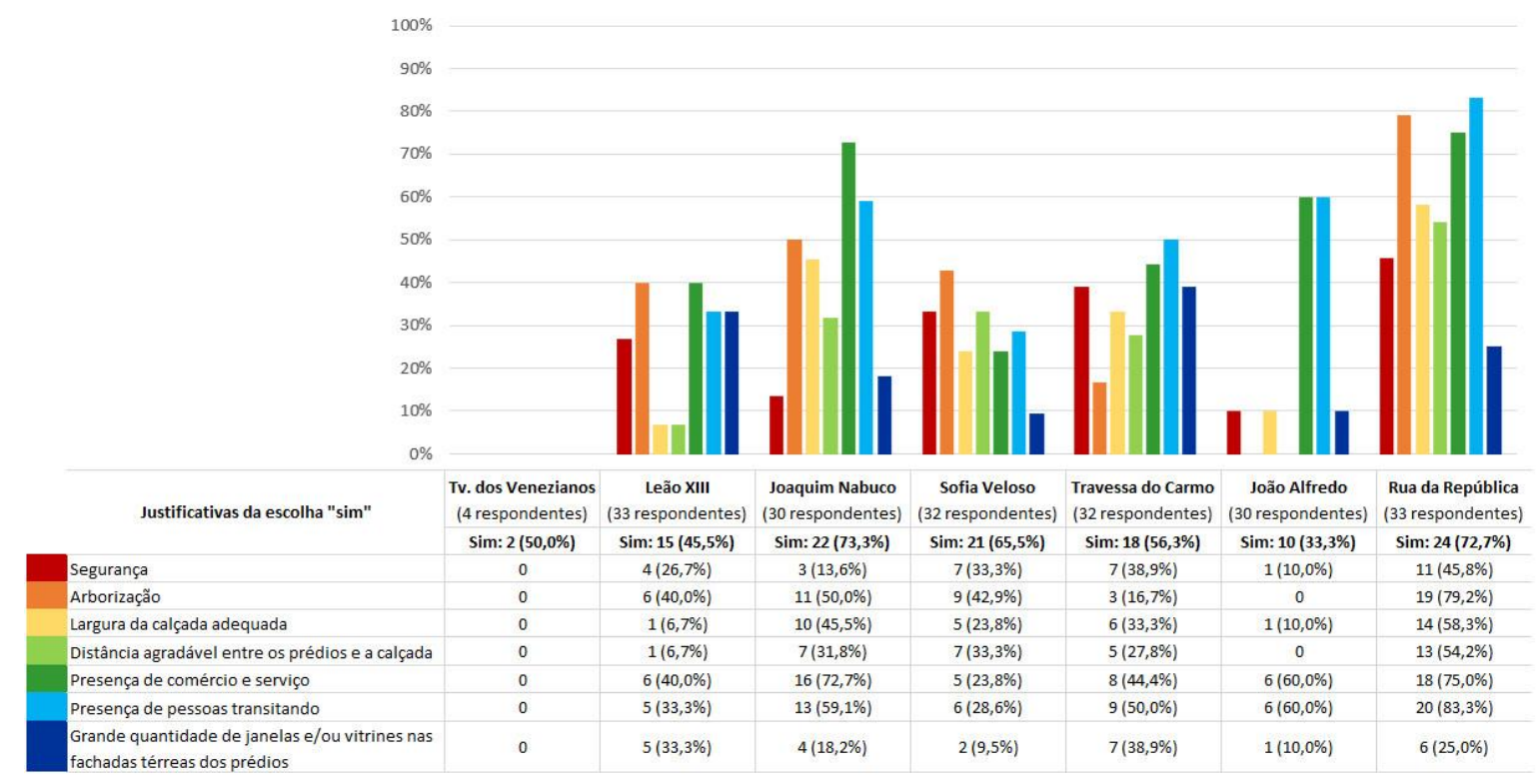

66 Knapp, C.; Silva, G. C. da; Reis, A. T. da L. 
Figura 13 - Justificativas para a escolha de não transitar na quadra caso não morasse nela

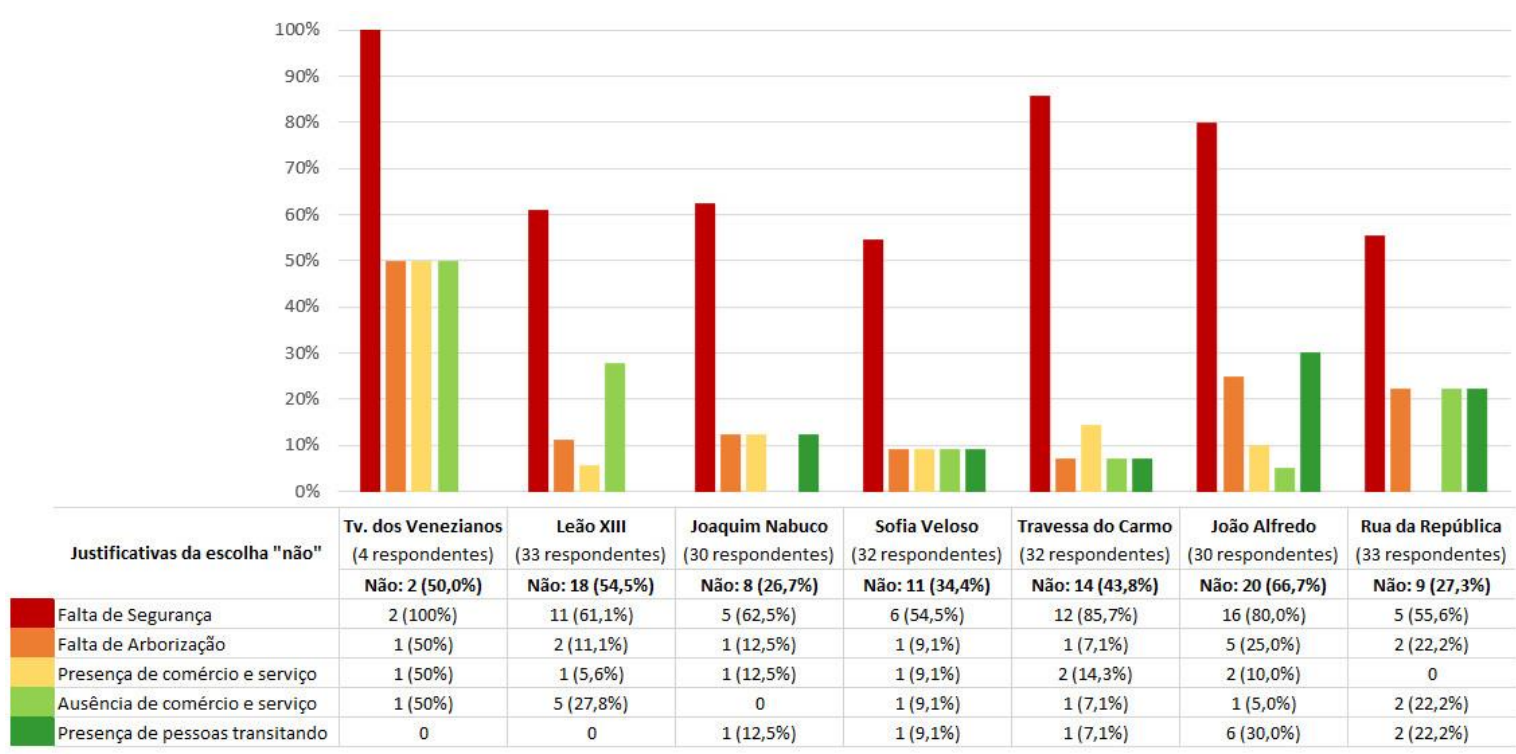

\section{Conclusão}

Os resultados revelam que as maiores quantidades de atividades opcionais (em movimento e estacionárias somadas), em ambos os turnos, estão em uma quadra (Rua da República) caracterizada pela quase totalidade das edificações alinhadas junto à calçada, pelo uso predominantemente não residencial (com a maior diversidade de usos), com a segunda maior taxa de permeabilidade visual $(0,3160)$ e funcional $(0,1538)$. Da mesma forma, nessa quadra estão as maiores taxas de atividades em movimento durante o dia (opcionais: 0,6982; necessárias: 0,6543) e durante a noite (opcionais: 0,8349; necessárias: 0,7714), quando somadas as atividades opcionais e necessárias ou quando consideradas separadamente. Essas taxas (bem maiores do que nas outras quadras) revelam a intensidade das atividades, principalmente durante a noite. Nessa quadra também estão as maiores quantidades de atividades estacionárias durante o dia $(0,8691)$ e durante a noite $(2,9148)$ quando somadas as atividades opcionais e necessárias. Quando consideradas separadamente as atividades opcionais e necessárias, assim como discriminadas as atividades estacionárias (em pé e sentadas), verifica-se que todas as atividades opcionais e quase todas as necessárias, independentemente do turno e se em pé ou sentadas, são maiores ou bem maiores nessa quadra do que nas demais, com as maiores taxas ocorrendo durante a noite.

Por outro lado, as menores quantidades de atividades opcionais (Rua Leão XIII: diurna - 0,0528; noturna $0,1282)$ podem ser explicadas pelo uso predominantemente residencial $(96,67 \%)$ e pela menor taxa de permeabilidade funcional $(0,0528)$ em relação às outras seis quadras, bem menor do que na quadra da Rua da República. Adicionalmente, os resultados para essa quadra evidenciam que uma taxa maior de permeabilidade visual $(0,4267)$ e a existência de todas as edificações alinhadas junto à calçada não são suficientes para gerar taxas de atividades opcionais expressivas.

Este estudo também revela, com base nas correlações positivas entre as taxas de permeabilidade funcional e de atividades em movimento opcionais e estacionárias necessárias diurnas nas quadras, que a permeabilidade funcional apresenta maior potencial em afetar a ocorrência de tais atividades do que a permeabilidade visual. Nesse sentido, o fato de uma taxa de permeabilidade funcional de 15 ou mais acessos em $100 \mathrm{~m}$ de fachadas em um lado da quadra se revelar como adequada para contribuir para a existência dessas atividades nas quadras investigadas em Porto Alegre está em consonância com os resultados de estudo realizado em Nova York (WHYTE, 1990) acerca da contribuição da existência de pelo menos 13 portas em 100 m de quadra para uma maior vitalidade urbana. Ainda, estes resultados vão ao encontro do estudo de Gehl, Kaefer e Reigstad (2006), na cidade de Estocolmo, o qual indica que a concentração entre 10 e 20 portas em $100 \mathrm{~m}$ de fachadas propicia quadras mais atraentes para os deslocamentos a pé. Da mesma forma, o estudo de Figueiredo (2018), realizado em Caxias do Sul, demonstra que a presença acima de 10 portas em $100 \mathrm{~m}$ de quadra possibilita maior concentração de atividades estacionárias nos espaços abertos públicos. Adicionalmente, os resultados obtidos estão em sintonia com aqueles do estudo de Lopez (2007), feito em ruas comerciais de Madrid, que revelam que a redução da velocidade do pedestre é obtida a partir da 
existência de 11 a 14 acessos às edificações a cada $100 \mathrm{~m}$ de quadra, assim como de um índice de permeabilidade visual de aproximadamente $63 \%$.

Por sua vez, as correlações positivas entre as quantidades de atividades em movimento e estacionárias diurnas e noturnas nas quadras e as quantidades de uso comercial e de serviços nos térreos das edificações confirmam o potencial desses usos em gerar atividades nos espaços abertos públicos, principalmente atividades opcionais estacionárias. Assim, a quadra que registrou o maior número de atividades opcionais estacionárias (Rua da República) é também a de maior diversidade de uso comercial e de serviços (tais como bares, restaurantes, cafés, lojas e mercadinhos). Esses resultados estão em consonância com os de estudos realizados em cidades de diferentes países, onde atividades tais como parar na frente de vitrines para olhar o interior de uma loja ou ocupar as mesas de bares e cafés dispostas na calçada para apreciar a vida urbana são consequência dos usos nos térreos das edificações adjacentes (GEHL, 2010; MEHTA, 2009; GEHL; KAEFER; REIGSTAD, 2006). Esses resultados também corroboram aqueles encontrados em outros estudos, os quais revelam a existência de correlações positivas entre a diversidade de usos nos térreos e o movimento de pedestres na cidade do Rio de Janeiro (NETTO; VARGAS; SABOYA, 2012), de Florianópolis (SABOYA; VARGAS; NETTO, 2017), de Nova York (EWING et al., 2015) e de São Francisco (CERVERO; DUNCAN, 2003); e condizem com o maior movimento de pedestres também nos turnos da manhã e da noite realizado por meio de contagens do movimento de pedestres em Capão da Canoa, em quadra cuja taxa de usos comerciais e serviços nos térreos é maior (ANTOCHEVIZ; ARSEGO; REIS, 2019).

Adicionalmente, o fato de haver 10 térreos com usos comerciais (lojas, mercado, bares, cafés e restaurante) em $100 \mathrm{~m}$ na quadra com a maior quantidade de atividades opcionais (Rua da República), corrobora o resultado do estudo realizado em Caxias do Sul sobre a recomendação de uma densidade mínima de 10 lojas em 100 m de rua (FIGUEIREDO, 2018). A adequação de tal quantidade de térreos com usos comerciais também está em sintonia com estudos em cidades do Reino Unido que indicam pelo menos 11 fachadas ativas em 100 m de rua (MONTGOMERY, 1998) e com estudo realizado em Boston (MEHTA, 2009) que indica a existência de 11 ou mais térreos em $100 \mathrm{~m}$ destinados a cafés, restaurantes, bares e lojas tais como floricultura e livraria, e a serviços que atendem a necessidades diárias ou semanais (p.ex., lojas de conveniência, lavanderia). Por outro lado, a adequação de referida quantidade de usos comerciais não está em sintonia com estudos realizados em Changsha (China), Middlesbrough (Reino Unido), Nova York e Copenhagen (GEHL, 2010), que indicam a necessidade de pelo menos 15 lojas em $100 \mathrm{~m}$ de quadra para que elas contribuam para a otimização do uso nas quadras.

Além disso, as quadras mais utilizadas para atividades necessárias pelos moradores são caracterizadas pelo uso predominantemente não residencial e refletem a intensidade das taxas das atividades necessárias observadas nos turnos diurnos e noturnos, evidenciando a contribuição de tal uso para a presença de pessoas na quadra, tanto moradores quanto visitantes.

Também se verificou a importância para a existência de atividades opcionais estacionárias sentadas da existência de calçadas com boa largura (não inferiores a 4,5 m) e em bom estado de conservação ao longo da quadra, que possibilitam a colocação de mesas e cadeiras por bares e cafés, tal como na quadra na Rua da República. Assim, calçadas com tais características podem contribuir para a existência de atividades opcionais estacionárias sentadas nas quadras, principalmente durante a noite, atuando como extensões dos usos dos térreos das edificações, tais como bares e restaurantes, e, assim, proporcionar um uso que também poderia ser possibilitado por pequenos recuos das edificações (de até $6 \mathrm{~m}$ ). Os resultados também mostram, no caso de uma cidade como Porto Alegre, com as quatro estações bem definidas, a relevância da existência de vegetação, incluindo árvores de pequeno, médio e grande porte, na faixa de serviço das calçadas, para a agradabilidade e o aumento principalmente das atividades opcionais estacionárias na quadra, que dependem dos atributos do ambiente construído. Ainda, a existência de comércios e serviços e a presença de pessoas na rua revelam a importância desses aspectos para a decisão do morador de querer transitar ou não na quadra onde mora além da arborização e da largura da calçada. Por outro lado, a falta de segurança justifica a escolha daqueles moradores que escolheram por não transitar por suas quadras e pode ser parcialmente explicada em uma das quadras pelas baixas taxas de atividades em uma rua sem saída e, em outra, pela expressiva quantidade de pessoas atraídas pelos bares e casas noturnas que abrem a partir das $22 \mathrm{~h}$.

Ainda, as taxas de atividades opcionais e necessárias nas quadras com maior e menor uso diurno e noturno, assim como as taxas correlacionadas com essas atividades, nomeadamente as taxas de atividades nos térreos das edificações e as taxas de permeabilidade funcional, servem de referência para outros estudos e contribuem para o conhecimento existente sobre o tema abordado. 
Os resultados obtidos neste estudo também contribuem para ressaltar a importância da existência de atividades nos espaços abertos públicos para a atração de outras pessoas e, assim, para favorecer a redução de roubos a pedestres, principalmente durante a noite, turno com maior ocorrência desse tipo de crime em várias cidades, incluindo Porto Alegre (REIS; ELY JUNIOR; EISENHUT, 2019).

Concluindo, sem ignorar as limitações deste trabalho, por exemplo, com relação à quantidade de diferentes quadras analisadas, os resultados obtidos podem contribuir para uma melhor compreensão acerca dos efeitos no uso do espaço aberto público, como consequência da existência de edificações recuadas e no alinhamento do lote, de seus usos e níveis de permeabilidade visual e funcional nos térreos. Assim, tais resultados podem contribuir para o planejamento e desenho urbano, especificamente para o conhecimento acerca do posicionamento das edificações e das características de seus térreos, visando à concepção de espaços urbanos mais convidativos para o uso pelos pedestres. Todavia, salienta-se a importância da realização de novos estudos que tratem de análises de usos de setores urbanos com distintas características arquitetônicas e de usos nos térreos, a partir da quantificação dessas características e da percepção dos diferentes usuários do espaço aberto público.

\section{Referências}

ANTOCHEVIZ, F. B.; ARSEGO, C.; REIS, A. T. L. Transformações de interfaces térreas, uso e percepção de segurança em cidade litorânea. urbe - Revista Brasileira de Gestão Urbana, v. 11, p. 1-23, 2019.

CERVERO, R.; DUNCAN, M. Walking, bicycling, and urban landscapes: evidence from the San Francisco Bay Area. American Journal of Public Health, v. 93, n. 9, p. 1478-1483, 2003.

CULLEN, G. Paisagem urbana. Lisboa: Edições 70, 1983.

EWING, R. et al. Streetscape features related to pedestrian activity. Journal of Planning Education and Research, v. 36, n. 1, p. 1-11, 2015.

FIGUEIREDO, C. Interfaces térreas entre edificações e espaços abertos públicos: efeitos para a estética, uso e percepção de segurança urbana. Porto Alegre, 2018. 275 f. Dissertação (Mestrado em Planejamento Urbano e Regional) - Faculdade de Arquitetura, Universidade Federal do Rio Grande do Sul, Porto Alegre, 2018.

GEHL, J. Cities for people. Washington: Island, 2010.

GEHL, J. La humanización del espacio urbano: la vida social entre los edificios. Barcelona: Reverté, 2009.

GEHL, J.; KAEFER, J. K.; REIGSTAD, S. Close encounters with buildings. Urban Design International, v. 11, p. 29-47, 2006.

GOOGLE MY MAPS. [Mapa]. Disponível em: https:/www.google.com/intl/es/maps/about/mymaps/. Acesso em: 28 fev. 2020.

INSTITUTO BRASILEIRO DE GEOGRAFIA E ESTATÍSTICA. Número de domicílios particulares ocupados, pessoas residentes em domicílios particulares ocupados e média de moradores em domicílios particulares ocupados, por situação e localização de área. 2010. Disponível em: https://sidra.ibge.gov.br. Acesso em: 7 mar. 2021.

JACOBS, J. The death and life of great American cities. New York: Modern Library, 2011.

KRETZER, G.; SABOYA, R. T. Tipos arquitetônicos e diversidade de usos do solo: uma análise em duas escalas. Oculum Ensaios, v. 17, p. 1-21, 2020.

LOPEZ, T. G. Influencia de la configuración del borde público-privado: parámetros de diseño. Cuadernos de Investigación Urbanística, v. 52, p. 1-68, 2007.

MEHTA, V. Lively streets: determining environmental characteristics to support social behavior. Journal of Planning Education and Research, v. 27, n. 2, p. 165-187, 2007.

MEHTA, V. Look closely and you will see, listen carefully and you will hear: urban design and social interaction on streets. Journal of Urban Design, v. 14, n. 1, p. 29-64, 2009.

MEHTA, V. Walkable streets: pedestrian behavior, perception and attitudes. Journal of Urbanism, v. 3, n. 1, p. $217-245,2008$.

Atividades nos espaços abertos públicos: edificações com diferentes recuos frontais, níveis de permeabilidade e usos 69 
MONTGOMERY, J. Making a city: urban, vitality and urban design. Journal of Urban Design, v. 3, n. 1, p. 93-116, 1998.

NETTO, V. M. A cidade como resultado: consequências de escolhas arquitetônicas. In: NETTO, V. M. et al. (org.). Efeitos da arquitetura: os impactos da urbanização contemporânea no Brasil. 2. ed. Brasília: FRBH, 2017.

NETTO, V. M.; VARGAS, J. C.; SOBOYA, R. T. Os efeitos sociais da morfologia arquitetônica. urbe Revista Brasileira de Gestão Urbana, v. 2, n. 4, p. 261-282, 2012.

OPEN STREET MAP. Open Street Map. Disponível em: https://www.openstreetmap.org/\#map=15/30.0415/-51.2215. Acesso em: 17 ago. 2020.

REIS, A. T. da L.; ELY JUNIOR, C. F.; EISENHUT, C. da S. Atributos físico-espaciais e configuracionais de segmentos de ruas e ocorrências de roubos a pedestres. Ambiente Construído, Porto Alegre, v. 4, n. 19, p. 55-77, 2019.

SABOYA, R. T.; VARGAS, J. C.; NETTO, V. M. Fatores morfológicos da vitalidade urbana: uma investigação sobre arquitetura e seus efeitos. In: NETTO, V. M. et al. (org.). Efeitos da arquitetura: os impactos da urbanização contemporânea no Brasil. 2. ed. Brasília: FRBH, 2017.

VIVAN, M.; SABOYA, R. Arquitetura, espaço urbano e criminalidade: efeitos de visibilidade na distribuição de ocorrência de crimes. In: NETTO, V. M. et al. (org.). Efeitos da arquitetura: os impactos da urbanização contemporânea no Brasil. 2. ed. Brasília: FRBH, 2019.

WHYTE, W. City: rediscovering the center. New York: Anchor, 1990.

\title{
Chrystiane Knapp
}

Programa de Pós-Graduação em Planejamento Urbano e Regional | Universidade Federal do Rio Grande do Sul | Rua Sarmento Leite, 320, Centro | Porto Alegre - RS - Brasil | CEP 90050-170 | Tel.: (+595) 961705729 | E-mail: chrys.knapp@gmail.com

\section{Gabriela Costa da Silva}

Programa de Pós-Graduação em Planejamento Urbano e Regional | Universidade Federal do Rio Grande do Sul | Tel.: (51) 98135-6750 | Email: gs.arq@hotmail.com.br

\section{Antônio Tarcísio da Luz Reis}

Departamento de Arquitetura, Faculdade de Arquitetura | Universidade Federal do Rio Grande do Sul | Rua Sarmento Leite, $320,5^{\circ}$ Andar, Sala 510, Centro | Porto Alegre - RS - Brasil | CEP 90050-170 | Tel.: (51) 99215-5810 | E-mail: tarcisio@orion.ufrgs.br

\author{
Ambiente Construído \\ Revista da Associação Nacional de Tecnologia do Ambiente Construído \\ Av. Osvaldo Aranha, $99-3^{\circ}$ andar, Centro \\ Porto Alegre - RS - Brasil \\ CEP 90035-190 \\ Telefone: +55 (51) 3308-4084 \\ www.seer.ufrgs.br/ambienteconstruido \\ www.scielo.br/ac \\ E-mail: ambienteconstruido@ufrgs.br
}

